Methods of Analysis by the U.S. Geological Survey National Water Quality Laboratory-Determination of Arsenic and Selenium in Water and Sediment by Graphite Furnace-Atomic Absorption Spectrometry

By Sandra R. Jones and John R. Garbarino

U.S. GEOLOGICAL SURVEY

Open-File Report 98-639 


\section{U.S. DEPARTMENT OF THE INTERIOR \\ BRUCE BABBITT, Secretary \\ U.S. GEOLOGICAL SURVEY \\ Charles G. Groat, Director}

The use of firm, trade, and brand names in this report is for identification purposes only and does not constitute endorsement by the U.S. Government.

For additional information write to:

Copies of this report can be purchased from:

U.S. Geological Survey

Chief, National Water Quality Laboratory

Box 25046, Mail Stop 407

Federal Center

Denver, CO 80225-0425
U.S. Geological Survey

Branch of Information Services

Box 25286, Federal Center

Denver, CO 80225-0286 


\section{CONTENTS}

Page

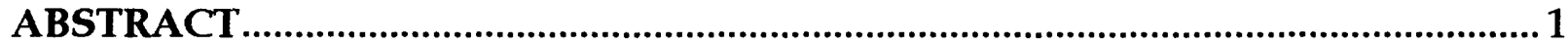

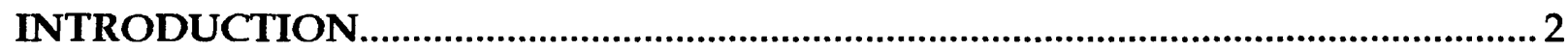

ANALYTICAL METHOD FOR ARSENIC AND SELENIUM .................................. 3

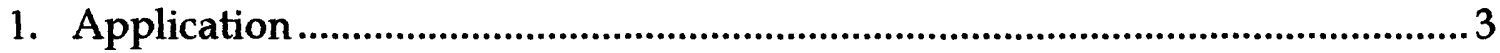

2. Summary of Method ...................................................................................... 3

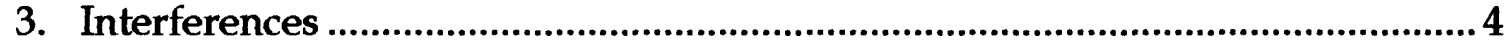

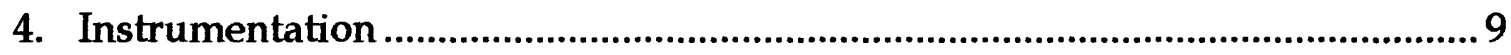

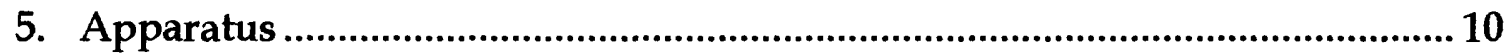

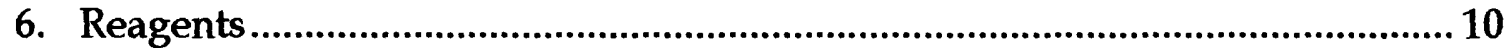

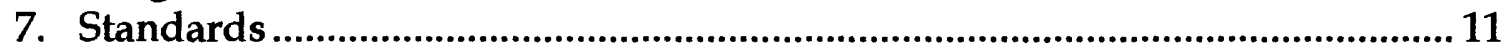

8. Sample preparation.......................................................................... 11

9. Instrumental performance.................................................................. 14

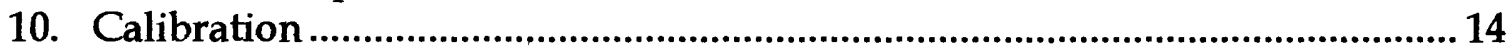

11. Procedure and data evaluation................................................................ 14

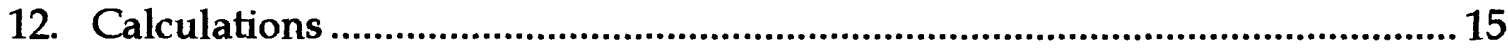

13. Reporting of results............................................................................... 16

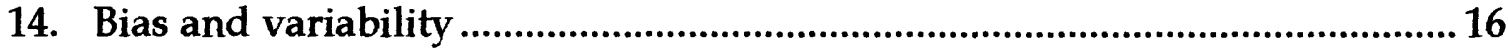

DISCUSSION OF RESULTS ........................................................................ 17

Method detection limit................................................................................... 17

Bias and variability data ............................................................................. 17

Standard reference materials .................................................................. 17

Spike recoveries in water samples.............................................................. 23

Analysis of water samples..................................................................... 31

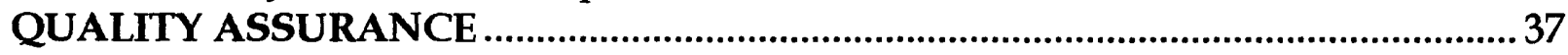

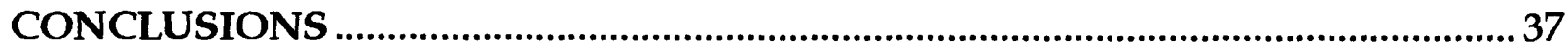

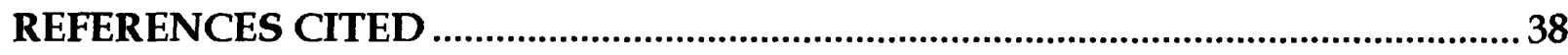




\section{FIGURES}

Figures 1-13. Graphs showing:

1. Arsenic measurements using low-flow and stop-flow conditions during atomization of solutions that contain increasing concentrations of sulfate and chloride from aluminum sulfate, calcium sulfate, iron sulfate, manganese sulfate, sodium sulfate, and sodium chloride.

2. Typical arsenic and selenium atomization profiles for a sample having $\mathbf{1 0 0}$ milligrams per liter aluminum in one percent nitric acid matrix

3. Selenium measurements using low-flow and stop-flow conditions during atomization of solutions that contain increasing concentrations of sulfate and chloride from aluminum sulfate, calcium sulfate, iron sulfate, manganese sulfate, sodium sulfate, and sodium chloride.

4. Spike recovery measurements for dissolved and whole-water recoverable arsenic by graphite furnace-atomic absorption spectrometry using stop flow and low flow during atomization in association with specific conductance.

5. Spike recovery measurements for dissolved and whole-water recoverable arsenic by graphite furnace-atomic absorption spectrometry using stop flow and low flow during atomization in association with sulfate concentration.

6. Spike recovery measurements for dissolved and whole-water recoverable arsenic by graphite furnace-atomic absorption spectrometry using stop flow and low flow during atomization in association with chloride concentration.

7. Spike recovery measurements for dissolved and whole-water recoverable selenium by graphite furnace-atomic absorption spectrometry using stop flow and low flow during atomization in association with specific conductance.

8. Spike recovery measurements for dissolved and whole-water recoverable selenium by graphite furnace-atomic absorption spectrometry using stop flow and low flow during atomization in association with sulfate concentration.

9. Spike recovery measurements for dissolved and whole-water recoverable selenium by graphite furnace-atomic absorption spectrometry using stop flow and low flow during atomization in association with chloride concentration. 


\section{FIGURES-Continued}

10. Results for the determination of dissolved arsenic in filtered water samples analyzed by graphite furnace-atomic absorption spectrometry (GF-AAS) using stop-flow and low-flow conditions relative to hydride generation-atomic absorption spectrometry (HG-AAS).

11. Results for the determination of dissolved selenium in filtered water samples analyzed by graphite furnace-atomic absorption spectrometry (GF-AAS) using stop-flow and low-flow conditions relative to hydride generation-atomic absorption spectrometry (HG-AAS).

12. Results for the determination of whole-water recoverable arsenic in nonfiltered water samples analyzed by graphite furnace-atomic absorption spectrometry (GF-AAS) using stop-flow and low-flow conditions relative to hydride generation-atomic absorption spectrometry (HG-AAS).

13. Results for the determination of whole-water recoverable selenium in nonfiltered water samples analyzed by graphite furnace-atomic absorption spectrometry (GF-AAS) using stop-flow and low-flow conditions relative to hydride generation-atomic absorption spectrometry (HG-AAS). 


\section{TABLES}

Table 1. Arsenic and selenium concentrations in synthetic whole-water standards digested using hydrochloric acid in-bottle, nitric acid inbottle, and other digestion procedures.

2. Method detection limits and analytical precision for low-flow and stopflow graphite furnace-atomic absorption spectrometry.

3. Bias and variability for the determination of arsenic in standard reference materials using low-flow graphite furnace-atomic absorption spectrometry.

4. Bias and variability for the determination of arsenic in standard reference materials using stop-flow graphite furnace-atomic absorption spectrometry.

5. Bias and variability for the determination of selenium in standard reference materials using low-flow graphite furnace-atomic absorption spectrometry.

6. Bias and variability for the determination of selenium in standard reference materials using stop-flow graphite furnace-atomic absorption spectrometry.

7. Percent recoveries in spiked laboratory reagent-water, ground-water, and surface-water samples by graphite furnace-atomic absorption spectrometry.

8. Chemical characteristics of all water samples used to evaluate graphite furnace-atomic absorption spectrometry.

9. Summary of statistical analysis results for graphite furnace-atomic absorption spectrometry and hydride generation-atomic absorption spectrometry. 


\section{CONVERSION FACTORS, ABBREVIATED WATER-QUALITY UNITS AND ADDITIONAL ABBREVIATIONS}

Multiply

gram (g)

liter $(\mathrm{L})$

microgram $(\mu \mathrm{g})$

microliter $(\mu \mathrm{L})$

milligram (mg)

milliliter $(\mathrm{mL})$

nanometer (nm)

picogram (pg)
By

$3.53 \times 10^{-2}$

$3.38 \times 10^{1}$

$3.53 \times 10^{-8}$

$3.38 \times 10^{-5}$

$3.53 \times 10^{-5}$

$3.38 \times 10^{-5}$

$3.94 \times 10^{-8}$

$3.53 \times 10^{-14}$
To obtain

ounce, avoirdupois

ounce, fluid

ounce, avoirdupois

ounce, fluid

ounce, avoirdupois

ounce, fluid

inch

ounce, avoirdupois

Degree Celsius $\left({ }^{\circ} \mathrm{C}\right)$ may be converted to degree Fahrenheit $\left({ }^{\circ} \mathrm{F}\right)$ by using the following equation:

$$
\mathrm{oF}^{\circ}=9 / 5\left({ }^{\circ} \mathrm{C}\right)+32 \text {. }
$$

Abbreviated water-quality units used in this report:

$\mathrm{mg} / \mathrm{L} \quad$ milligram per liter

$\mathrm{mL} / \mathrm{min} \quad$ milliliters per minute

$\mu \mathrm{g} / \mathrm{g} \quad$ microgram per gram

$\mu \mathrm{g} / \mathrm{L} \quad$ microgram per liter

$\mu \mathrm{S} / \mathrm{cm} \quad$ microsiemens per centimeter at 25 degrees Celsius

Other abbreviations used in this report:

As arsenic

a-s absorbance-second

ASTM American Society for Testing and Materials

FEP fluorinated ethylene propylene

GF-AAS graphite furnace-atomic absorption spectrometry

HG-AAS hydride generation-atomic absorption spectrometry

HGA heated graphite atomizer

ICP-MS inductively coupled plasma-mass spectrometry

$M$ molarity (moles per liter)

MDL method detection limit

Mo characteristic mass

MRL method reporting level

NIST National Institute of Standards and Technology

NWQL National Water Quality Laboratory

$\mathrm{Se}$ selenium 
Other abbreviations used in this report-Continued

sp gr specific gravity

SRWS Standard Reference Water Samples

STPF stabilized temperature platform furnace

THGA transverse heated graphite atomizer

USGS U.S. Geological Survey

$\mathrm{v} / \mathrm{v} \quad$ volume per volume

$\mathrm{w} / \mathrm{v} \quad$ weight per volume

WWR whole-water recoverable 


\title{
METHODS OF ANALYSIS BY THE U.S. GEOLOGICAL SURVEY NATIONAL WATER QUALITY LABORATORY - \\ DETERMINATION OF ARSENIC AND SELENIUM IN WATER AND SEDIMENT BY GRAPHITE FURNACE-ATOMIC ABSORPTION SPECTROMETRY
}

\author{
By Sandra R. Jones and John R. Garbarino
}

\begin{abstract}
Graphite furnace-atomic absorption spectrometry (GF-AAS) is a sensitive, precise, and accurate technique that can be used to determine arsenic and selenium in samples of water and sediment. The GF-AAS method has been developed to replace the hydride generation-atomic absorption spectrometry (HG-AAS) methods because the method detection limits are similar, bias and variability are comparable, and interferences are minimal. Advantages of the GFAAS method include shorter sample preparation time, increased sample throughput from simultaneous multielement analysis, reduced amount of chemical waste, reduced sample volume requirements, increased linear concentration range, and the use of a more accurate digestion procedure. The linear concentration range for arsenic and selenium is $\mathbf{1}$ to 50 micrograms per liter $(\mu \mathrm{g} / \mathrm{L})$ in solution; the current method detection limit for arsenic in solution is $0.9 \mu \mathrm{g} / \mathrm{L}$; the method detection limit for selenium in solution is $1 \mu \mathrm{g} / \mathrm{L}$.

This report describes results that were obtained using stop-flow and low-flow conditions during atomization. The bias and variability of the simultaneous determination of arsenic and selenium by GF-AAS under both conditions are supported with results from standard reference materials - water and sediment, real water samples, and spike recovery measurements. Arsenic and selenium results for all Standard Reference Water Samples analyzed were within one standard deviation of the most probable values. Long-term spike recoveries at $6.25,25.0$, and $37.5 \mu \mathrm{g} / \mathrm{L}$ in reagent-, ground-, and surface-water samples for arsenic averaged $103 \pm 2$ percent using low-flow conditions and $104 \pm 4$ percent using stop-flow conditions. Corresponding recoveries for selenium were $98 \pm 13$ percent using low-flow conditions and $87 \pm 24$ percent using stop-flow conditions. Spike recoveries at $25 \mu \mathrm{g} / \mathrm{L}$ in 120 water samples ranged from 97 to 99 percent for arsenic and from 82 to 93 percent for selenium, depending on the flow conditions used. Statistical analysis of dissolved and whole-water recoverable analytical results for the same set of water samples indicated that there is no significant difference between the GF-AAS and HG-AAS methods.

Interferences related to various chemical constituents were also identified. Although sulfate and chloride in association with various cations might interfere with the determination of arsenic and selenium by GF-AAS, the use of a magnesium nitrate/palladium matrix modifier and low-flow argon during atomization helped to.minimize such interferences. When using stabilized temperature platform furnace conditions where stop flow is used during atomization, the addition of hydrogen (5 percent volume/volume) to the argon minimized chemical interferences. Nevertheless, stop flow during atomization was found to be less effective than low flow in reducing interference effects.
\end{abstract}




\section{INTRODUCTION}

Arsenic is a metallic element whose compounds are used in insecticides, weed killers, lead shot, semiconductor devices, various alloys, pressure-treated wood products, and in glass, enamel, and ceramic manufacturing. Selenium, a nonmetallic element, is used in pigments, photographic exposure meters, electronics, and xerography. In addition, both elements can be found in mineral deposits that can be solubilized through erosion processes. Their significance to water quality is important because arsenic and selenium can be toxic to organisms and humans.

The U.S. Geological Survey National Water Quality Laboratory (NWQL) has developed a new graphite furnace-atomic absorption spectrometry (GF-AAS) method to replace the hydride generation-atomic absorption spectrometry (HG-AAS) methods for the analysis of arsenic and selenium (Fishman and Friedman, 1989). The arsenic method (I-2062-85, I-4062-85, I-6062-85) has a method reporting limit (MRL) of $1 \mu \mathrm{g} / \mathrm{L}$ and a linear analytical range of 1 to 20 $\mu \mathrm{g} / \mathrm{L}$; the selenium method (I-2667-85, I-4667-85, I-6667-85) has an MRL of $1 \mu \mathrm{g} / \mathrm{L}$ and a linear analytical range of 1 to $15 \mu \mathrm{g} / \mathrm{L}$. The GF-AAS method was developed for the simultaneous determination of arsenic and selenium in water and sediment and offers comparable sensitivity, bias and variability, reduces chemical waste, saves time, and extends the linear range from 1 to $50 \mu \mathrm{g} / \mathrm{L}$.

The HG-AAS methods each require about $15 \mathrm{~mL}$ of sample, a digestion procedure to oxidize organic species, and a procedure to reduce the element to the appropriate oxidation state. In contrast, GF-AAS requires less than $1 \mathrm{~mL}$ of sample and no additional preparatory procedures. In the GF-AAS method, about $30 \mu \mathrm{L}$ of water or aqueous sample is placed directly into a graphite tube, dried and atomized into ground-state atoms. The excited ground-state atoms absorb light from an electrodeless discharge lamp in an amount that is directly proportional to the concentration of arsenic or selenium in the sample.

Arsenic and selenium determination by GF-AAS requires four basic steps: drying, pyrolysis, atomization, and cleanout. After the sample is pipetted into the pyrolytically coated graphite tube, the tube is purged with a continuous flow of argon and gently heated to dryness. Following the drying step, the temperature is raised to the pyrolysis or charring temperature. After pyrolysis, the tube may be cooled (optional) followed by rapid heating (less than 1 second) to the atomization temperature. Gas flow through the tube then is lowered or stopped, and the sample is atomized into the optical path where the light absorption is measured. Following atomization, the gas flow is increased and a high-temperature clean-out step is used to prepare the graphite tube for the next sample.

This report describes a method developed by the U.S. Geological Survey (USGS) for use at the NWQL for the simultaneous determination of arsenic and selenium by GF-AAS. The method supplements other methods of the USGS for determination of arsenic and selenium in water and sediment samples that are described by Fishman and Friedman (1989). This method was implemented at the NWQL on October 1, 1998. 


\section{ANALYTICAL METHOD FOR ARSENIC AND SELENIUM}

\section{Inorganic Constituents and Parameter Codes}

Arsenic, dissolved, $\mathrm{I}-2063-98(\mu \mathrm{g} / \mathrm{L}$ as As): 01000

Arsenic, whole-water recoverable, I-4063-98 ( $\mu \mathrm{g} / \mathrm{L}$ as As): 01002

Arsenic, total recoverable in bed sediment, dry weight, I-6063-98 $(\mu \mathrm{g} / \mathrm{g}$ as As): 01003

Selenium, dissolved, I-2668-98 ( $\mu \mathrm{g} / \mathrm{L}$ as Se): 01145

Selenium, whole-water recoverable, I-4668-98 ( $\mu \mathrm{g} / \mathrm{L}$ as Se): 01147

Selenium, total recoverable in bed sediment, dry weight, I-6668-98 ( $\mu \mathrm{g} / \mathrm{g}$ as Se): 01148

\section{Application}

1.1 This method is used to analyze filtered and nonfiltered (also referred to as whole water) water samples for the determination of dissolved and whole-water recoverable (WWR) arsenic and selenium, and bed sediment (also referred to as bottom material) for total recoverable arsenic and selenium. By use of a 30- $\mu \mathrm{L}$-sample injection, the linear analytical range is from 1 to $50 \mu \mathrm{g} / \mathrm{L}$ for arsenic and selenium. Samples that contain arsenic or selenium concentrations that exceed the upper limit of the analytical range need to be diluted and reanalyzed or analyzed by an alternate method.

1.2 Furnace temperature programs, volumes, matrix modifiers, and other instrumental settings may be modified provided that the method detection limit (MDL) is equivalent or lower and characteristic mass is maintained. Characteristic mass $\left(M_{0}\right)$ best describes instrumental and operational performance using Perkin Elmer ${ }^{\mathrm{TM}}$ instrumentation; it is defined as the mass of an element in picograms required to produce a signal of 0.0044 absorbance-second (a-s). The characteristic mass is used to optimize and evaluate instrument performance (Beaty, 1988).

\section{Summary of method}

The simultaneous determination of arsenic and selenium by GF-AAS requires that a small (microliter) volume of sample be pipetted into a graphite tube. The tube is held between two graphite rings with quartz windows at each end, which produces a nearly closed environment to enhance the absorbance signal. The tube is pyrolytically coated with highdensity carbon to reduce the formation of nonvolatile carbides to prevent surface adsorption of the sample onto the walls of the graphite tube, and to increase tube life (Ghe and others, 1983). The sample is evaporated to dryness, charred, and atomized by using specified temperatures and high-temperature ramping. The absorbance signal is measured and compared to standards. 


\section{Interferences}

Two types of interferences affect GF-AAS analyses - spectral and nonspectral. The most common type of spectral interference is background absorption where undissociated molecular forms of matrix materials produce broadband absorption spectra. Zeeman background correction compensates for broadband absorption by using a strong magnetic field to shift the electronic energy levels of an element's atom. The shifted atomic spectrum can then be differentiated from the background spectrum (Beaty, 1988). Atoms having absorption wavelengths unresolved from the elemental absorption wavelength cause either positive or negative errors when measuring the element concentration profile (Flajnik-Rivera and Delles, 1996).

Sufficient energy must be available during atomization to dissociate the element and create free atoms. The composition of the sample matrix interferes with this process and results in either positive or negative errors. Matrix vapor condensation takes place not only in endheated graphite atomizer-type furnaces, but also in spatially isothermal, transverse heated graphite atomizer-type furnaces (Frech and L'Vov, 1993). It has also been shown that atoms can be trapped on the surface of condensed matrix particles and deposited at the cooler tube ends, resulting in a depression of the element signal. Introducing a low flow of inert gas during the atomization step can eliminate this type of interference. However, using low flow causes some loss of sensitivity because some of the atoms are swept from the chamber (Frech and L'Vov, 1993). This report demonstrates that either stop-flow or low-flow conditions can be used to determine arsenic and selenium, although low-flow conditions are preferred for routine sample analysis at the NWQL.

\subsection{Arsenic interferences}

The determination of $25-\mu \mathrm{g} / \mathrm{L}$ arsenic in solutions that contain increasing concentrations of various compounds of sulfate and chloride, including aluminum sulfate, calcium sulfate, iron sulfate, manganese sulfate, sodium sulfate, and sodium chloride is shown in figure 1 . Up to $3,000 \mathrm{mg} / \mathrm{L}$ of each sulfate compound and by $7,500 \mathrm{mg} / \mathrm{L}$ of sodium chloride were tested. Arsenic measurements are generally unaffected by using stop-flow or low-flow conditions for all metal salts added except for aluminum sulfate. All recovery measurements are within the acceptance criteria of $25 \pm 7.5 \mu \mathrm{g} / \mathrm{L}$ ( \pm 30 percent). However, although recoveries in aluminum sulfate are acceptable, the measurements were not reliable because of spectral interference. Aluminum interferes with arsenic at $193.7 \mathrm{~nm}$, causing false positive results (Flajnik-Rivera and Delles, 1996). Results showed that the spectral interference is significant for aluminum concentrations as low as $19 \mathrm{mg} / \mathrm{L}(100 \mathrm{mg}$-sulfate/L). Fortunately, aluminum concentrations in water samples analyzed at the NWQL rarely exceed $19 \mathrm{mg} / \mathrm{L}$ (the $75^{\text {th }}$ percentile is about 0.6 $\mathrm{mg} / \mathrm{L}$ ). In addition, the aluminum interference produces a unique atomization profile (see fig. 2) when using either low- or stop-flow conditions. A low, broad peak formation and high background peak formation with numerous spikes characterize the profiles. The spikes are less pronounced in the presence of sulfate because of higher background measurements produced. 


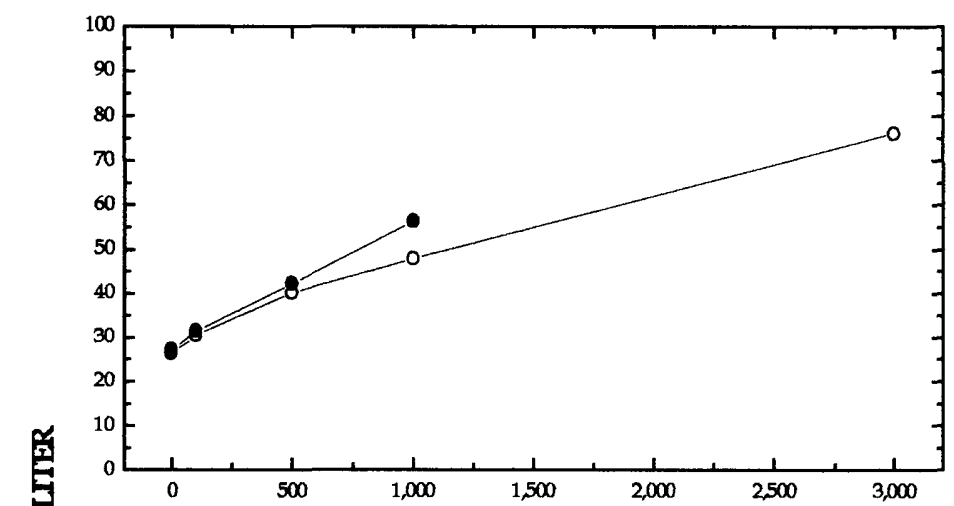

SULFATE CONCENTRATION FROM Al (SO $\left._{2}\right)_{g}$ IN MILLIGRAMS PER LITER

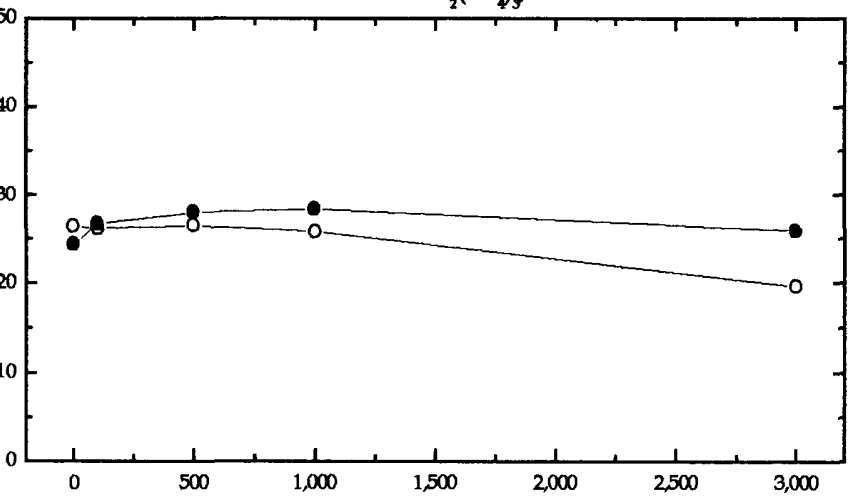

SULFATE CONCENTRATION FROM FESO, IN MILLIGRAMS PER LITER

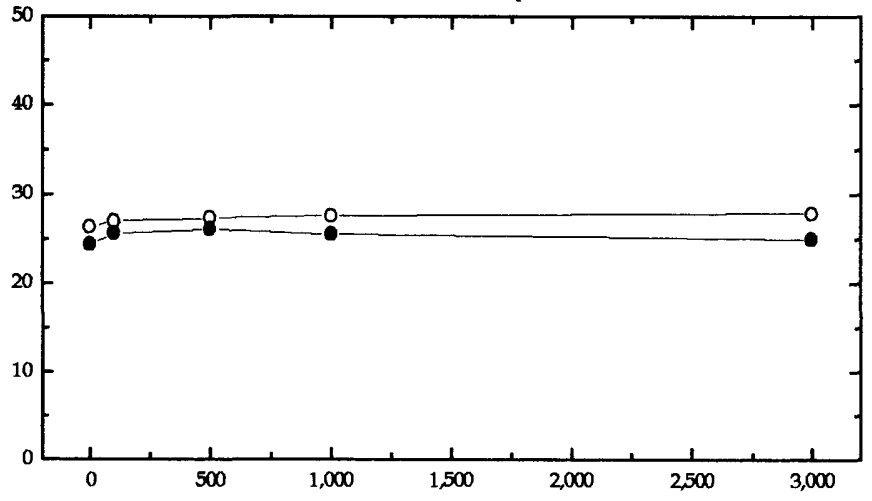

SULPATB CONCENTRATION FROM Na SO, IN MILLIGRAMS PBR LTTBR

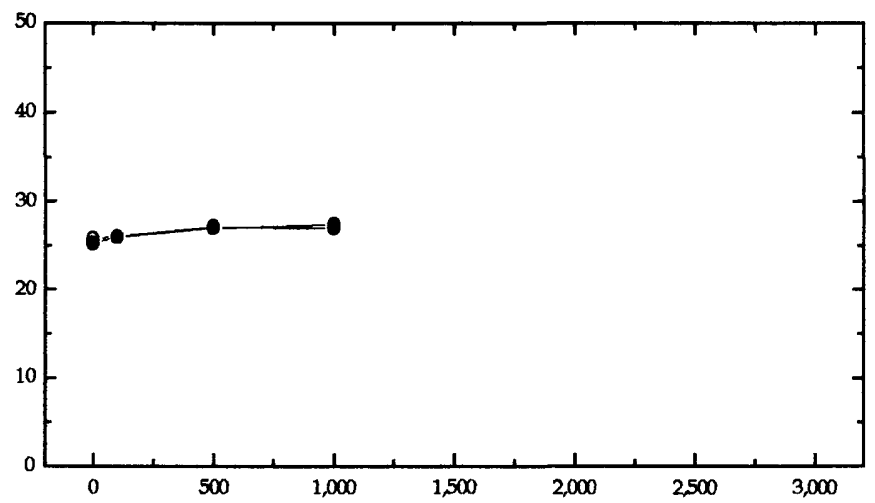

SULFATB CONCBNTRATION FROM CASO, IN MILLIGRAMS PER LITER

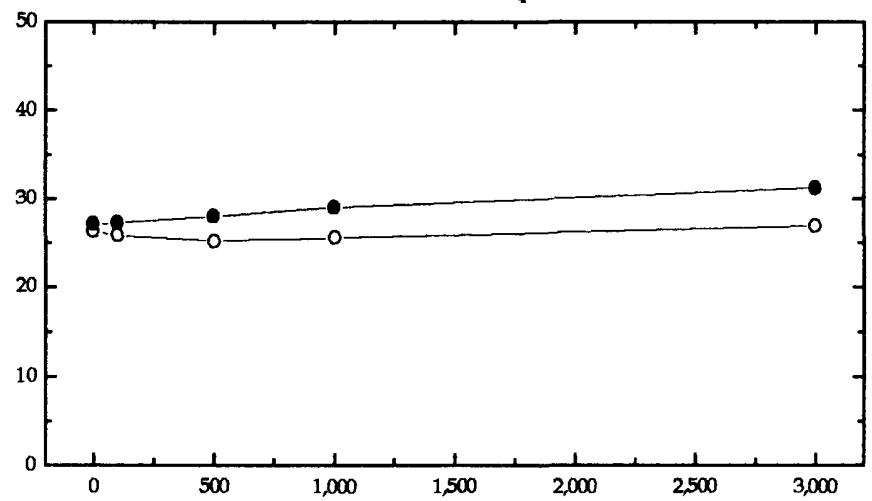

SULFATB CONCENTRATION FROM MnSO, IN MILLIGRAMS PER LTTER

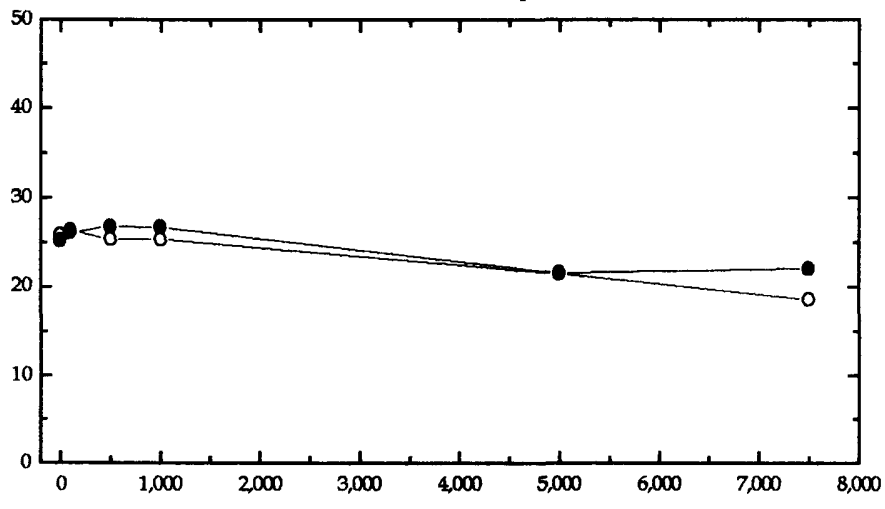

CHLORIDE CONCENTRATION FROMNAC, INMILLIGRAMS PER LITER

EXPLANATION

- - Low flow - - Stop flow

Figure 1. - Arsenic measurements using low-flow and stop-flow conditions during atomization of solutions that contain increasing concentrations of sulfate and chloride from aluminum sulfate, calcium sulfate, iron sulfate, manganese sulfate, sodium sulfate, and sodium chloride. 

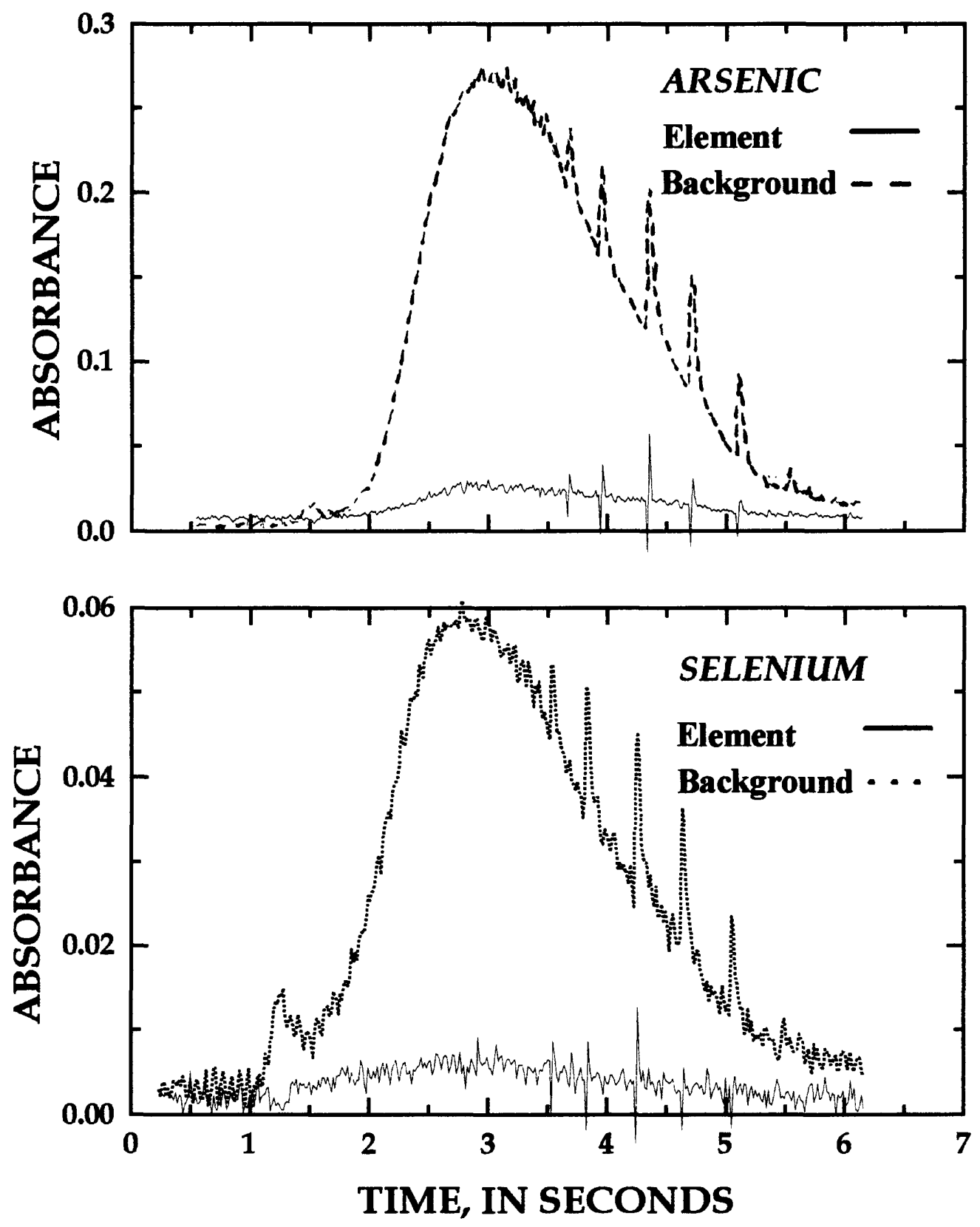

Figure 2.-Typical arsenic and selenium atomization profiles for a sample having 100 milligrams per liter aluminum in one percent nitric acid matrix. 


\subsection{Selenium interferences}

Lindberg and others (1988) have reported spectral and volatilization interferences on selenium. Selenium may be lost either by volatilization or by the formation of decomposition products, such as hydrogen selenide and selenium monoxide, which are not dissociated during the ashing and atomizing steps. Different modifiers, such as palladium, have been used to reduce volatilization losses (Lind berg and others, 1988).

The determination of $25 \mu \mathrm{g} / \mathrm{L}$ selenium in the same series of interference solutions as used for arsenic (see section 3.1) is shown in figure 3. As with arsenic, selenium absorption at $196.0 \mathrm{~nm}$ is affected by a spectral interference from aluminum. Unlike arsenic, selenium is not affected until aluminum concentrations reach greater than $90 \mathrm{mg} / \mathrm{L}$ aluminum $(500-1,000$ $\mathrm{mg} / \mathrm{L}$ sulfate), depending on the flow conditions.

Selenium is more prone to nonspectral type interferences than arsenic. It is especially susceptible to compounds such as iron sulfate and manganese sulfate, which are often present in water samples. Recoveries for selenium fell outside $25 \pm 7.5 \mu \mathrm{g} / \mathrm{L}$ ( \pm 30 percent) at $500 \mathrm{mg} / \mathrm{L}$ iron sulfate and at $1,000 \mathrm{mg} / \mathrm{L}$ manganese sulfate using stop-flow conditions, while low-flow conditions provided a stable environment up to $3,000 \mathrm{mg} / \mathrm{L}$. Low-flow conditions during atomization are advantageous in reducing such interferences (fig. 3 ). Sodium sulfate interferes at $3,000 \mathrm{mg} / \mathrm{L}$ for both stop- and low-flow conditions. Calcium sulfate does not interfere at $1,000 \mathrm{mg} / \mathrm{L}$. Selenium is stable in sodium chloride concentrations up to $7,500 \mathrm{mg} / \mathrm{L}$.

3.3 The high concentrations of metal salts used in this study to determine arsenic and selenium interferences normally are not encountered in water samples analyzed at the NWQL. However, such concentration levels can be present in acid mine drainage, saline estuaries, and some ground water. The primary purpose of using high metal salt concentrations was to establish the limitations of arsenic and selenium determined by GF-AAS. 

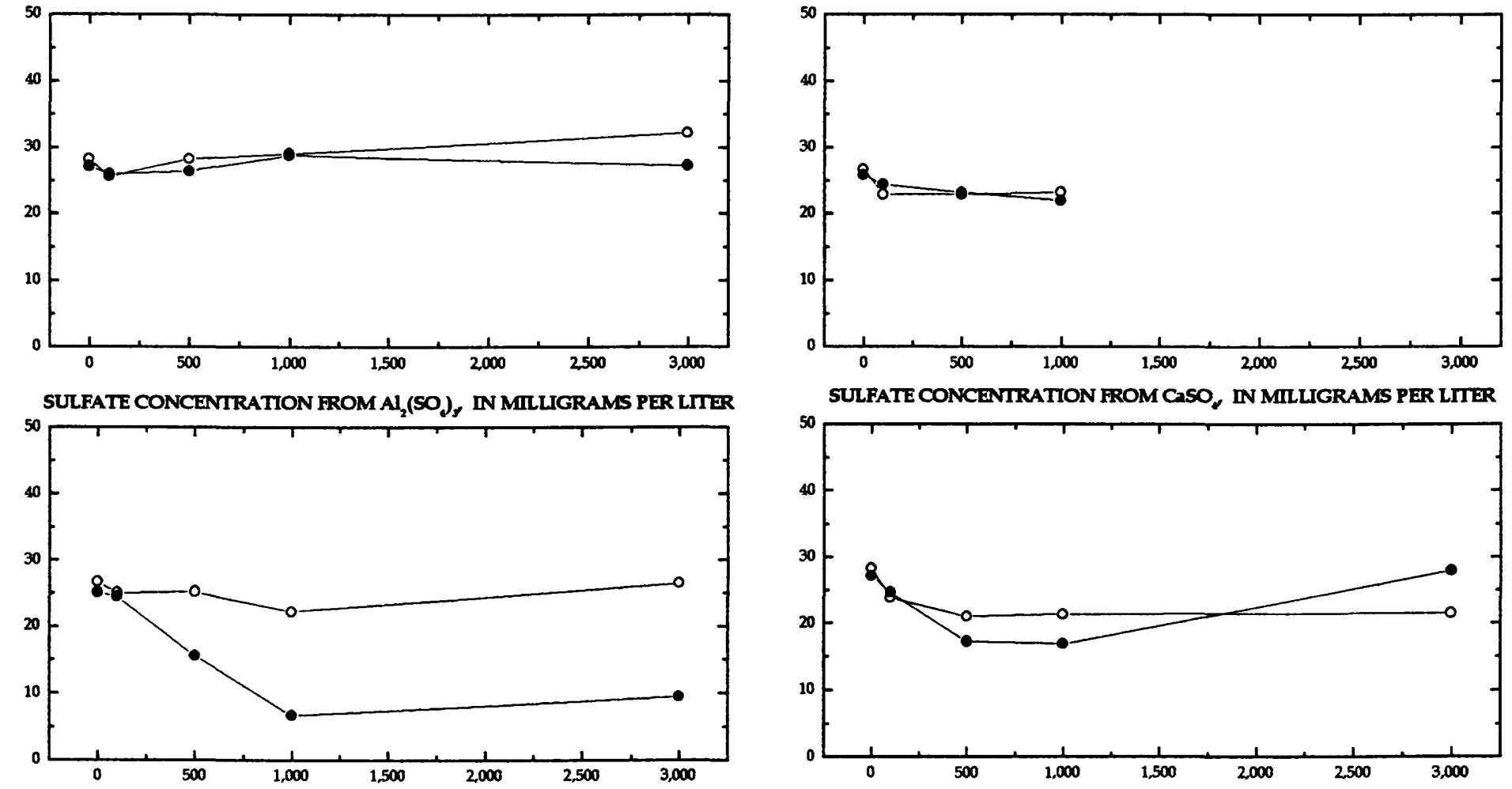

SULFATE CONCENIRATION FROM FESO, IN MILLIGRAMS PER LITER
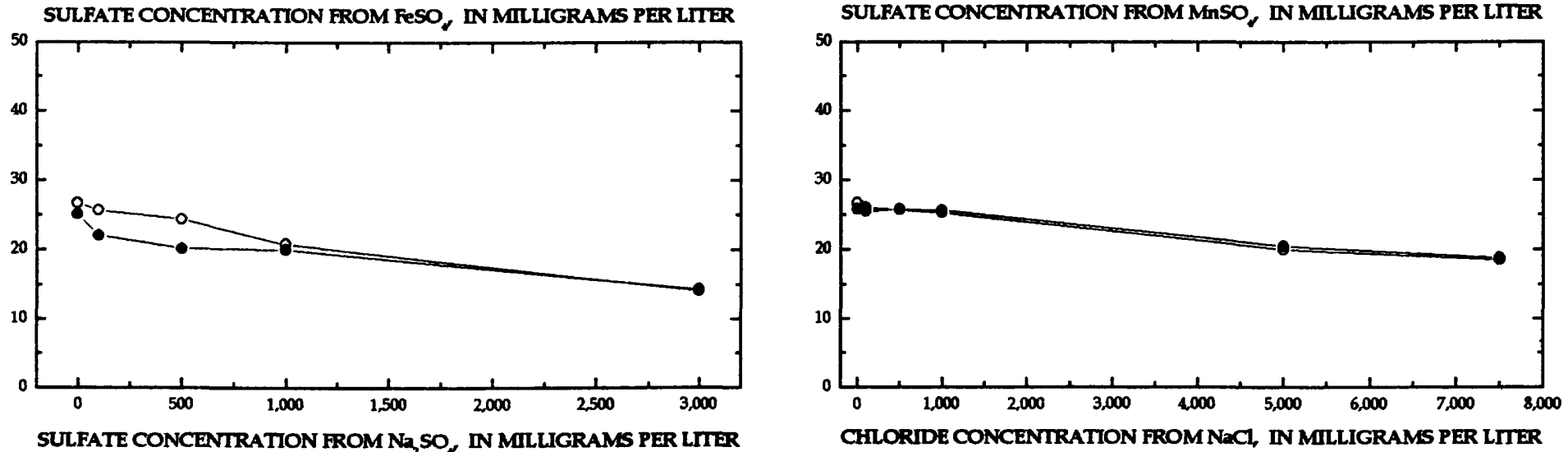

SULFATE CONCENTRATION FROM Na, SO, IN MLLIGRAMS PER LTIER

EXPLANATION

- - Low flow - - Stop flow

Figure 3.-Selenium measurements using low-flow and stop-flow conditions during atomization of solutions that contain increasing concentrations of sulfate and chloride from aluminum sulfate, calcium sulfate, iron sulfate, manganese sulfate, sodium sulfate, and sodium chloride. 


\section{Instrumentation}

4.1 The GF-AAS instrumentation used in this method must have a Zeemanbackground correction system, a digital integrator to quantitate peak area, a programmable temperature controller for high-temperature ramping, an autosampler, and a controllable gas flowrate. The graphite furnace must be capable of reaching a temperature sufficient to atomize arsenic and selenium. At present (1998) two types of graphite furnaces are acceptable for usethe heated graphite atomizer (HGA) and the transverse heated graphite atomizer (THGA). Data presented in this report were obtained using a simultaneous multielement THGA furnace. The multielement graphite furnace uses a beam combiner and enhanced detector system to determine up to six elements simultaneously. However, arsenic and selenium may be determined as single elements with somewhat improved method detection limits. Refer to Beaty (1988) and Beaty and Kerber (1993) for a complete description of furnace conditions and instrumental performance.

\subsection{Furnace Conditions}

Arsenic and selenium are determined simultaneously using conditions slightly different than what might be used on a conventional graphite furnace. Compromised pyrolysis and atomization temperatures are chosen for arsenic and selenium by adding 50 to $100^{\circ} \mathrm{C}$ to the lowest elemental pyrolysis temperature and by subtracting 50 to $100^{\circ} \mathrm{C}$ from the highest elemental atomization temperature.

The length of hold time maintained during pyrolysis is generally 25 to 30 seconds. However, because the sample matrix may broaden normal peak formations, it was found that a longer pyrolysis time of 50 to 60 seconds helped reduce matrix interferences. Consequently, in order to accommodate all matrices, a slightly higher atomization temperature with a longer hold time is used than might be used for more pristine sample matrices.

Both stop flow and low flow during atomization were investigated. Stabilized temperature platform (STPF) technology is a proven, accepted, and valuable technique for the analysis of samples by GF-AAS. One of its key requirements is to stop the flow of gas during atomization, thereby enhancing sensitivity. However, it may not always be advantageous to use stop flow because the use of low flow during atomization has been shown to reduce vaporphase and matrix interferences. All samples were analyzed using stop flow and low flow to demonstrate the usefulness of low flow during atomization.

Furnace conditions vary slightly between stop flow and low flow. Stop-flow conditions include argon mixed with 5 percent hydrogen to help reduce chloride interferences during the drying and pyrolysis steps (Creed and others, 1992). During pyrolysis, the furnace is purged with pure argon because the selenium signal might be suppressed if the matrix components are not purged prior to atomization. Although the THGA design by definition is transversely heated and should not have temperature gradients along the tube, inconsistencies are present (Frech and L'Vov, 1993). Since selenium is especially prone to vapor-phase interferences, 
a pre-atomization cooldown is also implemented to help promote a constant temperature along the tube during atomization.

Low-flow conditions consist of using an argon flow rate of $50 \mathrm{~mL} / \mathrm{min}$ through the furnace tube during atomization. Lower gas flows were not examined because the THGA design does not have that capability. Argon mixed with 5 percent hydrogen was used during drying and pyrolysis followed by a purge with pure argon, but the use of this gas mixture is considered optional. Its effectiveness under low-flow conditions was not determined. Endcapped tubes are recommended for low-flow conditions because they provide enhanced sensitivity and stability over the open-end tubes.

The use of palladium and magnesium nitrate as a matrix modifier is widely accepted for the determination of arsenic and selenium. Perkin Elmer ${ }^{\top M}$ has recommended modifier concentrations for each of its furnace designs; however, little or no difference was found for most sample matrices between the HGA or THGA concentrations. Nevertheless, the modifier concentration suggested for the HGA was found to be advantageous for complex sample matrices, especially matrices with increasing concentrations of iron.

\section{Apparatus}

5.1 Graphite furnace-atomic absorption spectrometer. See section 4, Instrumentation.

5.2 Graphite tubes with platform. Use pyrolytically coated graphite tubes for HGA or pyrolytically coated open-end or end-capped tubes for THGA.

5.3 Labware. Many metals adsorb easily to glassware surfaces. Use fluorinated ethylene propylene (FEP) labware to store standards and reagents.

5.4 Argon.

5.5 Argon with 5 percent hydrogen.

5.6 Arsenic electrodeless discharge lamp. Designed for a wavelength setting of 193.7 nanometers $(\mathrm{nm})$.

5.7 Selenium electrodeless discharge lamp. Designed for a wavelength setting of 196.0 nm.

\section{Reagents}

6.1 Matrix modifier solution, 0.3 percent weight/volume $(\mathrm{w} / \mathrm{v})$ palladium and 0.2 percent $\mathrm{w} / \mathrm{v} \mathrm{Mg}\left(\mathrm{NO}_{3}\right)_{2}$ in deionized water. Note that palladium is available in a solution of either hydrochloric acid $(\mathrm{HCl})$ or nitric acid $\left(\mathrm{HNO}_{3}\right)$. The use of palladium in $\mathrm{HCl}$ increases the likelihood of interferences because of the chloride present. 
6.2 Nitric acid, concentrated, ultrapure (sp gr 1.41): J.T. Baker Ultrex brand $\mathrm{HNO}_{3}$ has been found to be adequately pure; however, check each lot for contamination. Use for sample preservation.

6.3 Deionized water: All references to deionized water shall be understood to mean Type I reagent water (American Society for Testing and Materials, 1995, p. 122-124).

6.4 Nitric acid, 10 percent. In a 1-L volumetric flask containing about $500 \mathrm{~mL}$ of deionized water, add $100 \mathrm{~mL}$ of concentrated $\mathrm{HNO}_{3}$, then fill to volume with deionized water.

6.5 Deionized water, acidified: Add $4.0 \mathrm{~mL}$ ultrapure concentrated $\mathrm{HNO}_{3}$ to each liter of deionized water for a final concentration of 0.4 percent.

\section{Standards}

7.1 Arsenic, selenium standard solution $I, 1.00 \mathrm{~mL}=1,000 \mu \mathrm{g}$ As and Se: Use commercially prepared and certified As and Se calibration standards, 1,000 mg/L, 0.100 percent $\mathrm{w} / \mathrm{v}$.

7.2 Arsenic, selenium standard solution II, $1.00 \mathrm{~mL}=100.0 \mu \mathrm{g}$ As and Se: Dilute $10.0 \mathrm{~mL}$ each As, Se standard solution I to $100 \mathrm{~mL}$ (NOTE 1).

NOTE 1. Use acidified deionized water to prepare all dilutions. Store all standards in sealed FEP containers. Standards stored for 12 months yielded concentrations equal to freshly prepared solutions.

7.3 Arsenic, selenium standard solution III, $1.00 \mathrm{~mL}=1.00 \mu \mathrm{g}$ As and Se: Dilute $10.0 \mathrm{~mL}$ of As, Se standard solution II to $1,000 \mathrm{~mL}$.

7.4 Arsenic, selenium working standard solution $I, 1.00 \mathrm{~mL}=0.010 \mu \mathrm{g}$ As and Se: Dilute $10.0 \mathrm{~mL}$ of As, Se standard solution III to $1,000 \mathrm{~mL}$.

7.5 Arsenic, selenium working standard solution II, $1.00 \mathrm{~mL}=0.025 \mu \mathrm{g}$ As and Se: Dilute $25.0 \mathrm{~mL}$ of As, Se standard solution III to $1,000 \mathrm{~mL}$.

7.6 Arsenic, selenium working standard solution III, $1.00 \mathrm{~mL}=0.050 \mu \mathrm{g}$ As and Se: Dilute $50.0 \mathrm{~mL}$ of As, Se standard solution III to $1,000 \mathrm{~mL}$.

\section{Sample preparation}

8.1 Filtered, acidified water samples analyzed by GF-AAS for dissolved arsenic and selenium do not require additional sample preparation.

8.2 Nonfiltered, acidified water samples analyzed by GF-AAS for WWR arsenic and selenium require either the $\mathrm{HCl}$ in-bottle digestion procedure described by Hoffman and others (1996) or the modified procedure using only $\mathrm{HNO}_{3}$ described in the following section 8.4. All 
of the GF-AAS results for nonfiltered samples provided in this report are based on the standard in-bottle digestion.

8.3 Prepare bed sediment using method P-0520-85 prior to sampling (Fishman and Friedman, 1989, p. 45). Obtain a representative sample of the bed sediment by either coring (method P-0810-85) or splitting (method P-0811-85) (Fishman and Friedman, 1989, p. 46-48). Weigh up to a $1-\mathrm{g}$ subsample into a clean $250-\mathrm{mL}$ polyethylene bottle and add $100 \mathrm{~mL}$ of acidified deionized water (see section 6.5). Digest this mixture using either the standard inbottle digestion procedure (Hoffman and others, 1996) or the $\mathrm{HNO}_{3}$ procedure described in section 8.4 .

8.4 An in-bottle digestion using only $\mathrm{HNO}_{3}$ is advantageous for reducing interference effects from chloride. The standard in-bottle digestion procedure described by Hoffman and others (1996) is modified to use $1.6 \mathrm{~mL}$ of concentrated $\mathrm{HNO}_{3}$ instead of concentrated $\mathrm{HCl}$ for each $50 \mathrm{~mL}$ of sample - the proportion by volume. The remainder of the digestion procedure is unchanged. The accuracy of using the $\mathrm{HNO}_{3}$ digestion procedure was validated with results obtained for a series of standard reference materials. Synthetic wholewater samples were prepared by weighing 200 to $600 \mathrm{mg}$ of each standard reference material from the National Institute of Standards and Technology (NIST) 2704 Buffalo River Sediment, 1645 Riverine Sediment, or 1646 Estuarine Sediment into $400 \mathrm{~mL}$ of acidified deionized water. In addition, U.S. Geological Survey whole-water standard reference WW-1 was used. These synthetic whole-water samples were digested using the standard in-bottle procedure, the $\mathrm{HNO}_{3}$ in-bottle procedure, and two other on-line digestion procedures specific to the HG-AAS methods (Fishman and Friedman, 1989); the arsenic and selenium hydride methods use a sulfuric acid/potassium persulfate digestion. Since bed-sediment samples are prepared in a manner similar to whole-water samples, the same synthetic whole-water samples can be used to represent bed-sediment samples.

Results from GF-AAS, HG-AAS, and inductively coupled plasma-mass spectrometry (ICP-MS) for each of the digestion procedures is shown in table 1 . The results from GF-AAS and ICP-MS indicate that there is no significant difference in the arsenic concentration measured in the synthetic whole-water samples whether $\mathrm{HCl}$ or $\mathrm{HNO}_{3}$ is used, although there is a slight difference between methods. The effects of high concentrations of $\mathrm{HCL}$ on the determination of arsenic by GF-AAS were determined by removing the $\mathrm{HCl}$ from an aliquot of synthetic whole-water digest from the standard in-bottle procedure. The $\mathrm{HCl}$ was removed by evaporating the aliquot to dryness at $85^{\circ} \mathrm{C}$ and reconstituting the residue in 3 percent $\mathrm{HNO}_{3}$. Results for two of the synthetic whole-water samples indicated that removing the $\mathrm{HCl}$ had negligible effect. However, when $\mathrm{HCl}$ was removed from the riverine sedimentbased whole-water digest, the arsenic concentration was substantially higher (see table 1). The HG-AAS digestion procedure gave arsenic concentrations 25 to 300 percent less than the inbottle procedures. Such negative bias most likely results from an incomplete digestion, or particulate settling out in the sample tube prior to sample introduction, or both. This problem is aggravated because the synthetic whole-water samples have coarser sediment and higher sediment concentrations than are normally present in water samples submitted to NWQL. Data presented in the Discussion of Results section indicates there is no significant bias in WWR 
Table 1. - Arsenic and selenium concentrations in synthetic whole-water standards digested using hydrochloric acid in-bottle, nitric acid in-bottle, and other digestion procedures

$[\mu \mathrm{g} / \mathrm{g}$, microgram per gram; $\mu \mathrm{g} / \mathrm{L}$, microgram per liter; GF-AAS, graphite furnace-atomic absorption spectrometry; ICP-MS, inductively coupled plasma-mass spectrometry; HG-AAS,

hydride generation-atomic absorption spectrometry using sulfuric acid/potassium persulfate digestion for arsenic and potassium persulfate/hydrochloric acid/oxalic acid digestion for selenium; $\mathrm{HCl}$, standard in-bottle digestion using hydrochloric acid; $-\mathrm{HCl}$, standard in-bottle digestion but hydrochloric acid removed by evaporation; $\mathrm{HNO}_{3}$, in-bottle digestion using nitric acid; WW1, U.S. Geological Survey whole-water reference standard WW-1; BR, National Institute of Standards and Technology (NIST) Buffalo River sediment 2704; RS, NIST Riverine sediment 1645; ES, NIST Estuarine sediment 1646; na, not available; nd, none detected; \pm , plus or minus; the number of replicate digestions was 4 ]

\begin{tabular}{|c|c|c|c|c|c|c|}
\hline \multirow[b]{2}{*}{$\mu \mathrm{g} / \mathrm{g}$} & \multicolumn{3}{|c|}{ GF-AAS (low flow) } & \multicolumn{2}{|c|}{ ICP-MS } & \multirow{2}{*}{$\frac{\text { HG-AAS }}{\text { On-line }}$} \\
\hline & $\mathrm{HCl}$ & $-\mathrm{HCl}$ & $\mathrm{HNO}_{3}$ & $-\mathrm{HCl}$ & $\mathrm{HNO}_{3}$ & \\
\hline \multicolumn{7}{|c|}{ ARSENIC } \\
\hline $\begin{array}{c}W W 1 \text {, in } \\
\mu \mathrm{g} / \mathrm{L}\end{array}$ & $19.8 \pm 0.3$ & $21 \pm 1$ & na & $18.13 \pm 0.09$ & na & $5 \pm 1$ \\
\hline BR & $15.3 \pm 0.4$ & $15.4 \pm 0.6$ & $16.8 \pm 0.3$ & $14.3 \pm 0.2$ & $13.4 \pm 0.1$ & $11.0 \pm 0.9$ \\
\hline RS & $44 \pm 1$ & $51 \pm 3$ & $46 \pm 2$ & $42 \pm 1$ & $36.6 \pm 0.9$ & $27.6 \pm 0.4$ \\
\hline ES & $9.0 \pm 0.2$ & $9.7 \pm 0.1$ & $10.08 \pm 0.05$ & $7.72 \pm 0.05$ & $7.34 \pm 0.05$ & $3.2 \pm 0.8$ \\
\hline \multicolumn{7}{|c|}{ SELENIUM } \\
\hline $\begin{array}{c}W W 1, \text { in } \\
\mu \mathrm{g} / \mathrm{L}\end{array}$ & $4.3 \pm 0.2$ & $4.7 \pm 0.7$ & na & $4.8 \pm 0.1$ & na & $4.7 \pm 0.3$ \\
\hline BR & nd & $1.0 \pm 0.8$ & $1.0 \pm 0.8$ & $0.8 \pm 0.1$ & $0.44 \pm 0.08$ & $0.6 \pm 0.05$ \\
\hline RS & nd & nd & nd & $0.64 \pm 0.08$ & $0.36 \pm 0.04$ & $0.8 \pm 0.1$ \\
\hline ES & nd & $1.0 \pm 0.1$ & $0.78 \pm 0.06$ & $0.67 \pm 0.03$ & $0.69 \pm 0.05$ & $0.43 \pm 0.07$ \\
\hline
\end{tabular}

arsenic results from GF-AAS presumably because of the low sediment concentrations in the water samples.

Selenium concentrations for WW-1 indicate there is no significant difference between the HGAAS on-line digestion procedure and the standard in-bottle procedure (see table 1). However, at concentrations near the MDLs for low-flow GF-AAS, possible interferences from chloride are indicated. Selenium was not detected in any NIST-based whole-water digest using the $\mathrm{HCl}$ (standard) in-bottle digestion by GF-AAS. However, when the $\mathrm{HCl}$ is removed, selenium concentrations correspond to the $\mathrm{HNO}_{3}$ in-bottle results for two of the three samples. Even though the selenium concentrations are near the MDLs for GF-AAS and HG-AAS, the results compare reasonably well with ICP-MS. Results presented in the Discussion of Results section show that there is no significant difference between results from HG-AAS and GF-AAS even though different digestion procedures were used. 


\section{Instrumental performance}

Instrumental performance (see section 1.2) is best demonstrated by characteristic mass and MDL measurements. See section 12 for calculating characteristic mass. Typical Perkin Elmer characteristic mass settings for different instrumentation is provided in the following table:

\begin{tabular}{cccc} 
Instrument & Tube type & Arsenic, pg & Selenium, pg \\
\cline { 1 - 2 } & Grooved tube & 15 & 28 \\
THGA & Open-end & 40 & 45 \\
THGA & Closed-end & 22 & 28
\end{tabular}

These characteristic mass measurements are obtained using stop flow during atomization and in a nonsimultaneous mode. Perkin Elmer has not established instrumental characteristic mass measurements for low flow during atomization. Using a $50-\mu \mathrm{g} / \mathrm{L}$ standard and a $30-\mu \mathrm{L}$ injection, the characteristic mass measurements for arsenic and selenium by simultaneous analysis on a THGA using a closed-end tube and stop flow during atomization averaged $25 \mathrm{pg}$ (+14 percent) for arsenic and $33 \mathrm{pg}(+16$ percent) for selenium. By using low-flow conditions, the characteristic mass was $46 \mathrm{pg}$ for arsenic and $56 \mathrm{pg}$ for selenium. These measurements, which were calculated using the instrumental settings specified for a THGA open-end tube under stop-flow conditions, indicated the difference for arsenic is +15 percent and selenium is +24 percent, demonstrating that the sensitivity using low-flow conditions is comparable to that of using an open-end tube with stop-flow atomization.

\section{Calibration}

A calibration curve is constructed by analyzing a blank and a minimum of three working standards using a linear regression analysis. The correlation coefficient must be equal to or greater than 0.999 .

\section{Procedure and data evaluation}

\subsection{Analyze samples in a clean contaminant-free environment.}

11.2 Rinse the sample cups at least twice with sample before filling. Place the cups in sample tray and cover. Adjust the autosampler so that only the injection tip contacts the sample.

11.3 Analyze blanks prior to sample analysis to condition a new graphite tube and to verify that acidified water and modifier are not contaminated. Contamination is present when an artificially low bias occurs causing negative values (near $-1.0 \mu \mathrm{g} / \mathrm{L}$ or more following calibration) for samples near detection. Pouring another aliquot of blank or matrix modifier, or both, usually alleviates contamination. If the acidified water, the modifier, or both are contaminated at their source(s), prepare fresh solutions by using a new bottle or lot of acid or matrix modifier chemicals as necessary. If contamination persists, troubleshoot by replacing the graphite tube, cleaning the contact rings, or replacing the autosampler tip and tubing. 
11.4 Inject matrix modifier (see note 2) with each aliquot of calibration blank and a minimum of three standards to construct the calibration curve from the absorbance-second measurements. sample.

11.5 Similarly, analyze samples by injecting matrix modifier (see note 2) with each

11.6 Analyze a quality-control sample (for example, a USGS Standard Reference Water Sample, SRWS) immediately following calibration and after every tenth sample (minimum). Analyze a reagent blank with each set of samples. See the Quality Assurance section regarding quality control.

NOTE 2: Currently (1998), $7 \mu \mathrm{L}$ of matrix modifier is used for each $30-\mu \mathrm{L}$ sample.

\section{Calculations}

12.1 Calculation of characteristic mass $\left(\mathrm{M}_{\mathrm{O}}\right)$ in picograms

$\mathrm{M}_{\mathrm{O}}=\underline{\text { sample volume }(\mu \mathrm{L}) \times \text { element concentration }(\mu \mathrm{g} / \mathrm{L}) \times 0.0044 \mathrm{a}-\mathrm{s}}$ observed peak area (a-s)

Acceptable ranges using stop-flow include an interval difference of $\pm 20 \%$

Percent difference $=\left[\left(\right.\right.$ calculated $M_{o}$ - instrument $\left.M_{o}\right) /\left(\right.$ instrument $\left.\left.M_{0}\right)\right] \times 100$

12.2 Calculation of percent spike recovery

Percent spike recovery $=\left[\left(S_{s p}-S\right) / S p k\right] \times 100$

Where $S_{s p}$ equals the spiked sample concentration, $S$ equals the unspiked sample concentration, and Spk equals the theoretical spike concentration.

12.3 Calculation of concentration in bed sediment

As or Se $(\mu \mathrm{g} / \mathrm{g})=\frac{\mu \mathrm{g} / \mathrm{L} \text { As or Se } \times 0.1 \mathrm{~L}}{\text { Wt of sample }(\mathrm{g})}$ 


\section{Reporting of results}

Currently (1998), report dissolved (01000), and WWR (01002) arsenic, and dissolved (01145), and WWR (01147) selenium concentrations as follows: Less than $1.0 \mu \mathrm{g} / \mathrm{L}$, as less than $1 \mu \mathrm{g} / \mathrm{L} ; 1$ to $100 \mu \mathrm{g} / \mathrm{L}$, to the nearest microgram per liter; $100 \mu \mathrm{g} / \mathrm{L}$ and greater, two significant figures. Report recoverable bed sediment (01003) arsenic and recoverable bed sediment (01148) selenium as follows: Less than $1.0 \mu \mathrm{g} / \mathrm{g}$ as less than $1 \mu \mathrm{g} / \mathrm{g} ; 1$ to $100 \mu \mathrm{g} / \mathrm{g}$, to the nearest microgram per gram; $100 \mu \mathrm{g} / \mathrm{g}$ and greater, two significant figures.

\section{Bias and variability}

The bias and variability of the method are determined by comparing results from the new method and a former official method with standard reference materials and water samples. See the following discussion for results. 


\section{DISCUSSION OF RESULTS}

\section{Method Detection Limit}

The MDL is defined as the minimum concentration of a substance that can be measured and reported with 99-percent confidence that the element concentration is greater than zero (U.S. Environmental Protection Agency, 1994a). The MDLs for low-flow and stop-flow conditions are listed in table 2. These MDLs were determined using the procedure described by the U.S. Environmental Protection Agency (1994).

The current (1998) MDLs listed in table 2 were determined by analyzing the MDL standard solution among a set of real water samples. This practice provides an MDL that more likely represents a level of detection that would be expected during routine analyses.

Table 2. - Method detection limits and analytical precision for low-flow and stop-flow graphite furnaceatomic absorption spectrometry

$[\mu \mathrm{g} / \mathrm{L}$, micrograms per liter; \% RSD, percent relative standard deviation;

MDL, method detection limit]

\begin{tabular}{lcccccc}
\hline $\begin{array}{l}\text { Theoretical } \\
\text { concentration } \\
\text { was 2.5 } \mu \mathrm{g} / \mathrm{L}\end{array}$ & $\begin{array}{c}\text { Experimental } \\
\text { mean } \\
\text { concentration } \\
(\mu \mathrm{g} / \mathrm{L})\end{array}$ & $\begin{array}{c}\text { Standard } \\
\text { deviation } \\
(\mu \mathrm{g} / \mathrm{L})\end{array}$ & $\%$ RSD & $t$-value & $\begin{array}{c}\text { Degrees } \\
\text { of } \\
\text { freedom } \\
(\mathrm{n}-1)\end{array}$ & $\begin{array}{c}\mathrm{MDL} \\
(\mu \mathrm{g} / \mathrm{L})\end{array}$ \\
\hline Low flow & & & & & & \\
Arsenic & 2.5 & 0.3 & 12 & 2.602 & 15 & 0.9 \\
Selenium & 2.6 & 0.4 & 15 & 2.602 & 15 & 1.1 \\
Stop flow & & & & & & \\
Arsenic & 2.2 & 0.3 & 14 & 2.583 & 16 & 0.7 \\
Selenium & 2.3 & 0.4 & 17 & 2.583 & 16 & 1.1 \\
\hline
\end{tabular}

\section{Bias and Variability Data}

\section{Standard reference materials}

The bias and variability of arsenic and selenium determinations by GF-AAS were verified by analyzing SRWS. Results for all standard reference materials were well within an acceptable one standard deviation of the mean (see tables 3 through 6). Every SRWS was treated and analyzed as a dissolved and WWR sample. 
Table 3. - Bias and variability for the determination of arsenic in standard reference materials using low-flow graphite furnace-atomic absorption spectrometry

$[\mu \mathrm{g} / \mathrm{L}$, micrograms per liter; $\mathrm{n}$, number of determinations; \% RSD, percent relative standard deviation; SRWS, U.S. Geological Survey Standard Reference Water Sample; WWR, wholewater recoverable digestion using in-bottle procedure by Hoffman and others (1996). Theoretical measurements are derived by USGS from interlaboratory results using various analytical methods]

\begin{tabular}{|c|c|c|c|c|c|c|}
\hline \multirow[b]{2}{*}{$\begin{array}{l}\text { Reference } \\
\text { material }\end{array}$} & \multicolumn{4}{|c|}{ Experimental } & \multicolumn{2}{|c|}{ Theoretical } \\
\hline & $\begin{array}{c}\text { Mean } \\
(\mu \mathrm{g} / \mathrm{L})\end{array}$ & $\begin{array}{c}\text { Standard } \\
\text { deviation } \\
(\mu \mathrm{g} / \mathrm{L})\end{array}$ & $\%$ RSD & $\mathbf{n}$ & $\begin{array}{c}\text { Mean } \\
(\mu \mathrm{g} / \mathrm{L})\end{array}$ & $\begin{array}{c}\text { Standard } \\
\text { deviation } \\
(\mu \mathrm{g} / \mathrm{L})\end{array}$ \\
\hline SRWS 119 & 4.4 & 0.6 & 13.6 & 19 & & \\
\hline WWR SRWS 119 & 3.7 & 0.5 & 13.5 & 8 & 4.2 & 1.2 \\
\hline SRWS 123 & 20.9 & 1.5 & 7.2 & 20 & & \\
\hline WWR SRWS 123 & 20.0 & 1.1 & 5.5 & 8 & 20.2 & 3.4 \\
\hline SRWS 125 & 9.9 & 0.8 & 8.1 & 17 & $10 ?$ & 20 \\
\hline WWR SRWS 125 & 10.1 & 0.4 & 4.0 & 5 & 10.2 & 2.0 \\
\hline SRWS 133 & 27.5 & 1.2 & 4.4 & 28 & 271 & 43 \\
\hline WWR SRWS 133 & 26.3 & 0.6 & 2.3 & 12 & 21.1 & 4.3 \\
\hline SRWS 135 & 10.7 & 0.8 & 7.5 & 15 & 100 & \\
\hline WWR SRWS 135 & 10.2 & 0.6 & 5.9 & 6 & 10.0 & 2.0 \\
\hline SRWS 139 & 5.8 & 0.5 & 8.6 & 20 & 56 & 14 \\
\hline WWR SRWS 139 & 5.0 & 0.6 & 12.0 & 6 & 0.0 & 1.4 \\
\hline SRWS 143 & 16.2 & 1.0 & 6.2 & 15 & $15 ?$ & 27 \\
\hline WWR SRWS 143 & 15.5 & 0.8 & 5.2 & 3 & 10.2 & 2.1 \\
\hline SRWS 145 & 10.2 & 0.7 & 6.9 & 13 & 00 & 20 \\
\hline WWR SRWS 145 & 9.0 & 0.7 & 7.8 & 10 & 9.9 & 2.0 \\
\hline
\end{tabular}


Table 4.-Bias and variability for the determination of arsenic in standard reference materials using stop-flow graphite furnace-atomic absorption spectrometry

[ $\mathrm{\mu g} / \mathrm{L}$, micrograms per liter; $\mathrm{n}$, number of determinations; \% RSD, percent relative standard deviation; SRWS, U.S. Geological Survey Standard Reference Water Sample; WWR, wholewater recoverable digestion using in-bottle procedure by Hoffman and others (1996). Theoretical measurements are derived by USGS from interlaboratory results using various analytical methods]

\begin{tabular}{|c|c|c|c|c|c|c|}
\hline \multirow[b]{2}{*}{$\begin{array}{l}\text { Reference } \\
\text { material }\end{array}$} & \multicolumn{4}{|c|}{ Experimental } & \multicolumn{2}{|c|}{ Theoretical } \\
\hline & $\begin{array}{c}\text { Mean } \\
(\mu \mathrm{g} / \mathrm{L})\end{array}$ & $\begin{array}{c}\text { Standard } \\
\text { deviation } \\
(\mu \mathrm{g} / \mathrm{L})\end{array}$ & $\%$ RSD & $\mathbf{n}$ & $\begin{array}{c}\text { Mean } \\
(\mu \mathrm{g} / \mathrm{L})\end{array}$ & $\begin{array}{c}\text { Standard } \\
\text { deviation } \\
(\mu \mathrm{g} / \mathrm{L})\end{array}$ \\
\hline SRWS 119 & 4.3 & 0.4 & 9.3 & 12 & & \\
\hline WWR SRWS 119 & 3.7 & 0.7 & 18.9 & 7 & 4.2 & 1.2 \\
\hline SRWS 123 & 21.2 & 1.0 & 4.7 & 11 & ? & 24 \\
\hline WWR SRWS 123 & 20.7 & 0.5 & 2.4 & 5 & 20.2 & 0.4 \\
\hline SRWS 125 & 10.1 & 0.5 & 5.0 & 5 & 10? & 20 \\
\hline WWR SRWS 125 & 9.8 & 0.9 & 9.2 & 4 & 10.2 & 2.0 \\
\hline SRWS 133 & 27.0 & 1.3 & 4.8 & 19 & 271 & 13 \\
\hline WWR SRWS 133 & 26.3 & 1.0 & 3.8 & 6 & 27.1 & 4.3 \\
\hline SRWS 135 & 10.3 & 0.6 & 5.8 & 8 & 100 & 20 \\
\hline WWR SRWS 135 & 10.4 & 1.6 & 15.4 & 7 & 10.0 & 2.0 \\
\hline SRWS 139 & 5.5 & 0.6 & 10.9 & 13 & & 11 \\
\hline WWR SRWS 139 & 6.2 & 1.1 & 17.7 & 4 & 5.6 & 1.4 \\
\hline SRWS 143 & 15.9 & 1.3 & 8.2 & 9 & 152 & 27 \\
\hline WWR SRWS 143 & 14.1 & 1.0 & 7.1 & 3 & 10.2 & 2.1 \\
\hline SRWS 145 & 9.6 & 0.8 & 8.3 & 12 & 00 & 20 \\
\hline WWR SRWS 145 & 9.6 & 0.4 & 4.2 & 7 & 9.9 & 2.0 \\
\hline
\end{tabular}


Table 5. - Bias and variability for the determination of selenium in standard reference materials using low-flow graphite furnace-atomic absorption spectrometry

$[\mu \mathrm{g} / \mathrm{L}$, micrograms per liter; $\mathrm{n}$, number of determinations; \% RSD, percent relative standard deviation; SRWS, U.S. Geological Survey Standard Reference Water Sample; WWR, wholewater recoverable digestion using in-bottle procedure by Hoffman and others (1996). Theoretical measurements are derived by USGS from interlaboratory results using various analytical methods]

\begin{tabular}{|c|c|c|c|c|c|c|}
\hline \multirow[b]{2}{*}{$\begin{array}{l}\text { Reference } \\
\text { material }\end{array}$} & \multicolumn{4}{|c|}{ Experimental } & \multicolumn{2}{|c|}{ Theoretical } \\
\hline & $\begin{array}{c}\text { Mean } \\
(\mu \mathrm{g} / \mathrm{L})\end{array}$ & $\begin{array}{c}\text { Standard } \\
\text { deviation } \\
(\mu \mathrm{g} / \mathrm{L})\end{array}$ & $\%$ RSD & $\mathrm{n}$ & $\begin{array}{c}\text { Mean } \\
(\mu \mathrm{g} / \mathrm{L})\end{array}$ & $\begin{array}{c}\text { Standard } \\
\text { deviation } \\
(\mu \mathrm{g} / \mathrm{L})\end{array}$ \\
\hline SRWS 119 & 9.8 & 0.7 & 7.1 & 19 & & \\
\hline WWR SRWS 119 & 8.9 & 0.7 & 7.9 & 9 & 9.8 & 2.6 \\
\hline SRWS 123 & 5.2 & 0.6 & 11.5 & 20 & & \\
\hline WWR SRWS 123 & 4.8 & 0.5 & 10.4 & 8 & 3.2 & 1.5 \\
\hline SRWS 125 & 10.0 & 0.7 & 7.0 & 18 & 08 & 76 \\
\hline WWR SRWS 125 & 10.2 & 0.3 & 2.9 & 3 & 7.0 & 2.0 \\
\hline SRWS 133 & 21.9 & 1.2 & 5.5 & 28 & 214 & \\
\hline WWR SRWS 133 & 22.3 & 0.6 & 2.7 & 12 & 21.4 & 0.4 \\
\hline SRWS 135 & 10.8 & 0.6 & 5.6 & 13 & & \\
\hline WWR SRWS 135 & 10.1 & 1.4 & 13.9 & 9 & 10.0 & 2.7 \\
\hline SRWS 139 & 4.7 & 0.6 & 12.8 & 20 & 0 & 11 \\
\hline WWR SRWS 139 & 4.3 & 0.8 & 18.6 & 6 & 4.8 & 1.4 \\
\hline SRWS 143 & 10.1 & 1.0 & 9.9 & 15 & 96 & 26 \\
\hline WWR SRWS 143 & 10.3 & 0.2 & 1.9 & 3 & 7.0 & 2.0 \\
\hline SRWS 145 & 10.3 & 0.7 & 6.8 & 13 & 101 & $?$ \\
\hline WWR SRWS 145 & 10.0 & 1.1 & 11.0 & 10 & 10.1 & 2.8 \\
\hline
\end{tabular}


Table 6.-Bias and variability for the determination of selenium in standard reference materials using stop-flow graphite furnace-atomic absorption spectrometry

$[\mu \mathrm{g} / \mathrm{L}$, micrograms per liter; $\mathrm{n}$, number of determinations; \% RSD, percent relative standard deviation; SRWS, U.S. Geological Survey Standard Reference Water Sample; WWR, wholewater recoverable digestion using in-bottle procedure by Hoffman and others (1996). Theoretical measurements are derived by USGS from interlaboratory results using various analytical methods]

\begin{tabular}{|c|c|c|c|c|c|c|}
\hline \multirow[b]{2}{*}{$\begin{array}{l}\text { Reference } \\
\text { material }\end{array}$} & \multicolumn{4}{|c|}{ Experimental } & \multicolumn{2}{|c|}{ Theoretical } \\
\hline & $\begin{array}{c}\text { Mean } \\
(\mu \mathrm{g} / \mathrm{L})\end{array}$ & $\begin{array}{c}\text { Standard } \\
\text { deviation } \\
(\mu \mathrm{g} / \mathrm{L})\end{array}$ & $\%$ RSD & $\mathrm{n}$ & $\begin{array}{c}\text { Mean } \\
(\mu \mathrm{g} / \mathrm{L})\end{array}$ & $\begin{array}{c}\text { Standard } \\
\text { deviation } \\
(\mu \mathrm{g} / \mathrm{L})\end{array}$ \\
\hline SRWS 119 & 9.4 & 0.5 & 5.3 & 12 & \multirow{2}{*}{9.8} & \multirow{2}{*}{2.6} \\
\hline WWR SRWS 119 & 8.8 & 0.9 & 10.2 & 7 & & \\
\hline SRWS 123 & 4.7 & 0.3 & 6.4 & 11 & \multirow{2}{*}{5.2} & \multirow{2}{*}{1.5} \\
\hline WWR SRWS 123 & 5.5 & 1.1 & 20.0 & 5 & & \\
\hline SRWS 125 & 9.4 & 0.6 & 6.4 & 9 & \multirow{2}{*}{9.8} & \multirow{2}{*}{2.6} \\
\hline WWR SRWS 125 & 9.7 & 1.3 & 13.4 & 4 & & \\
\hline SRWS 133 & 21.6 & 0.8 & 3.7 & 19 & \multirow{2}{*}{21.4} & \multirow{2}{*}{5.4} \\
\hline WWR SRWS 133 & 22.9 & 0.9 & 3.9 & 6 & & \\
\hline SRWS 135 & 9.8 & 0.8 & 8.2 & 9 & \multirow{2}{*}{10.0} & \multirow{2}{*}{2.7} \\
\hline WWR SRWS 135 & 10.3 & 1.1 & 11.4 & 7 & & \\
\hline SRWS 139 & 4.4 & 0.5 & 11.4 & 14 & \multirow{2}{*}{4.8} & \multirow{2}{*}{1.4} \\
\hline WWR SRWS 139 & 5.4 & 0.7 & 13.0 & 4 & & \\
\hline SRWS 143 & 10.3 & 2.0 & 19.4 & 9 & \multirow[b]{2}{*}{9.6} & \multirow{2}{*}{2.6} \\
\hline WWR SRWS 143 & 9.0 & 1.3 & 14.4 & 3 & & \\
\hline SRWS 145 & 9.3 & 0.6 & 6.5 & 12 & \multirow{2}{*}{10.1} & \multirow{2}{*}{2.7} \\
\hline WWR SRWS 145 & 10.4 & 0.7 & 6.7 & 7 & & \\
\hline
\end{tabular}


Validation of the new method requires bias and variability measurements be obtained on three different types of water matrices (M.J. Fishman and others, U.S. Geological Survey, written commun., 1998.) Matrices consist of reagent-, ground-, and surface-water samples. Each sample was fortified with $6.25,25.0$, and $37.5 \mu \mathrm{g} / \mathrm{L}$ arsenic and selenium and analyzed under low-flow and stop-flow conditions on nine nonconsecutive days to determine percent recovery. Percent recovery results are listed in table 7. The mean percent recoveries for arsenic in all matrix types are $103 \pm 2$ and $104 \pm 4$ percent using low-flow and stop-flow conditions, respectively; corresponding recoveries for selenium using low-flow and stop-flow conditions were $98 \pm 13$ and $87 \pm 24$ percent, respectively. Arsenic recoveries in all matrix types indicated negligible bias when using either low-flow or stop-flow conditions. However, selenium recoveries in the ground-water matrix were negatively biased by at least 30 percent when using either low-flow or stop-flow conditions. This bias results from the interference associated with high iron sulfate concentration (as shown in fig. 3); the ground-water matrix has $340 \mathrm{mg}$-iron/L and 2,300 mg-sulfate/L. In general, the variability in the selenium spike recoveries is about a factor of 5 greater than arsenic.

Table 7.-Percent recoveries in spiked laboratory reagent-water, ground-water, and surface-water samples by graphite furnace-atomic absorption spectrometry

$$
[\mu \mathrm{g} / \mathrm{L} \text {, micrograms per liter; } \pm \text {, plus or minus] }
$$

\begin{tabular}{lcccc}
\hline \multirow{2}{*}{$\begin{array}{c}\text { Spike } \\
(\mu \mathrm{g} / \mathrm{L})\end{array}$} & \multicolumn{2}{c}{$\begin{array}{c}\text { Arsenic (percent } \\
\text { recovery) }\end{array}$} & \multicolumn{2}{c}{$\begin{array}{c}\text { Selenium (percent } \\
\text { recovery) }\end{array}$} \\
\cline { 2 - 5 } & Low flow & Stop flow & Low flow & Stop flow \\
\hline Reagent-water matrix & & & & \\
6.25 & $102 \pm 5$ & $104 \pm 6$ & $111 \pm 7$ & $99 \pm 10$ \\
25.0 & $104 \pm 5$ & $102 \pm 7$ & $105 \pm 5$ & $105 \pm 6$ \\
37.5 & $102 \pm 6$ & $99 \pm 5$ & $103 \pm 6$ & $101 \pm 4$ \\
Ground-water matrix & & & & \\
6.25 & $100 \pm 11$ & $97 \pm 15$ & $72 \pm 12$ & $98 \pm 7$ \\
25.0 & $101 \pm 7$ & $103 \pm 9$ & $71 \pm 7$ & $105 \pm 4$ \\
37.5 & $105 \pm 5$ & $106 \pm 6$ & $72 \pm 8$ & $105 \pm 5$ \\
Surface-water matrix & & & & \\
6.25 & $102 \pm 13$ & $106 \pm 8$ & $97 \pm 16$ & $98 \pm 7$ \\
25.0 & $106 \pm 7$ & $108 \pm 6$ & $99 \pm 4$ & $105 \pm 4$ \\
37.5 & $105 \pm 6$ & $107 \pm 6$ & $101 \pm 4$ & $105 \pm 5$ \\
\hline
\end{tabular}




\section{Spike recoveries in water samples}

A representative set of about 120 water samples was chosen from various types of water submitted to the NWQL-surface water, ground water, acid mine drainage, and storm-water runoff. Every water sample chosen was spiked with $25 \mu \mathrm{g} / \mathrm{L}$ arsenic and selenium to identify possible interferences. Sample specific conductance, sulfate concentration, and chloride concentration were used as indicators of potential interferences. The range of concentrations of arsenic, selenium, chloride, and sulfate and the specific conductance for the set of samples are listed in table 8.

The relation of spike recoveries for arsenic to specific conductance, sulfate concentration, and chloride concentration is shown in figures 4 through 6 . The total number of samples plotted for each depends on the analyses requested for each sample; for example, chloride was not determined for all samples. A spike recovery range between 70 and 130 percent was used as the acceptance criteria (U.S. Environmental Protection Agency, 1994b).

Table 8. - Chemical characteristics of all water samples used to evaluate graphite furnace-atomic absorption spectrometry

$[\mu \mathrm{g} / \mathrm{L}$, microgram per liter; $\mathrm{mg} / \mathrm{L}$, milligram per liter; SC, specific conductance; $\mu \mathrm{S} / \mathrm{cm}$, microsiemens per centimeter at 25 degrees Celsius]

\begin{tabular}{lcccc}
\hline $\begin{array}{l}\text { Element or } \\
\text { constituent }\end{array}$ & $\begin{array}{c}\text { 25th per- } \\
\text { centile }\end{array}$ & Median & $\begin{array}{c}\text { 75th per- } \\
\text { centile }\end{array}$ & $\begin{array}{c}\text { Max- } \\
\text { imum }\end{array}$ \\
\hline Arsenic, in $\mu \mathrm{g} / \mathrm{L}$ & 1.7 & 2.9 & 7.4 & 104 \\
Selenium, in $\mu \mathrm{g} / \mathrm{L}$ & 2.9 & 4.5 & 8.2 & 34 \\
& & & & \\
Chloride, in mg/L & 9.8 & 68 & 501 & 9,176 \\
SC, in $\mu \mathrm{S} / \mathrm{cm}^{1}$ & 455 & 944 & 2,490 & 28,700 \\
Sulfate, in mg/L & 108 & 309 & 1,306 & 16,832 \\
\hline
\end{tabular}

1 Specific conductance for whole-water samples prior to digestion.

Both dissolved and WWR sample spike recoveries for arsenic (figs. 4-6) showed no significant trends with respect to specific conductance, sulfate, or chloride concentrations. Only one spike recovery did not satisfy the acceptance criteria when using low-flow conditions (the recovery was biased low). This sample had a specific conductance of 23,000 $\mu \mathrm{S} / \mathrm{cm}, 16,000 \mathrm{mg}$ sulfate/ $\mathrm{L}$, and $280 \mathrm{mg}$-chloride/ $\mathrm{L}$; all concentrations were considerably above the $90^{\text {th }}$ percentile of the samples submitted to NWQL. When using stop-flow conditions, four samples did not give acceptable recoveries (positive and negative bias). Specific conductance for these samples ranged from 600 to more than $27,000 \mu \mathrm{S} / \mathrm{cm}$. In general, results for the sample set indicated that the determination of arsenic using low-flow conditions is only marginally better than stop-flow conditions. Either flow condition was demonstrated to be accurate for samples with specific conductance as high as $28,700 \mu \mathrm{S} / \mathrm{cm}$, with sulfate concentrations in excess of $3,500 \mathrm{mg} / \mathrm{L}$, and with chloride concentrations in excess of $8,000 \mathrm{mg} / \mathrm{L}$. Specific conductance 


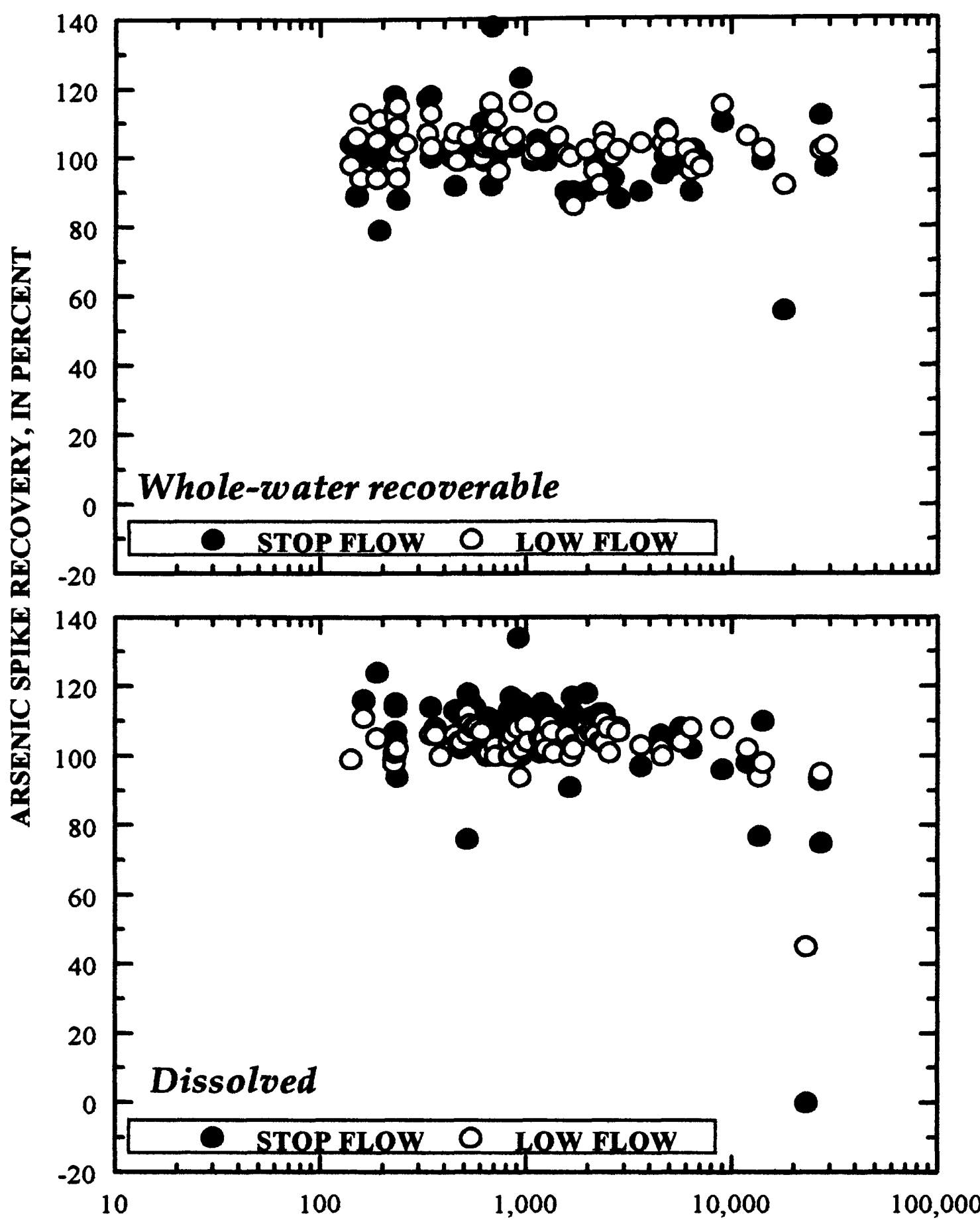

SPECIFIC CONDUCTANCE, IN MICROSIEMENS PER CENTIMETER

Figure 4. - Spike recovery measurements for dissolved and whole-water recoverable arsenic by graphite furnace-atomic absorption spectrometry using stop flow and low flow during atomization in association with specific conductance. 


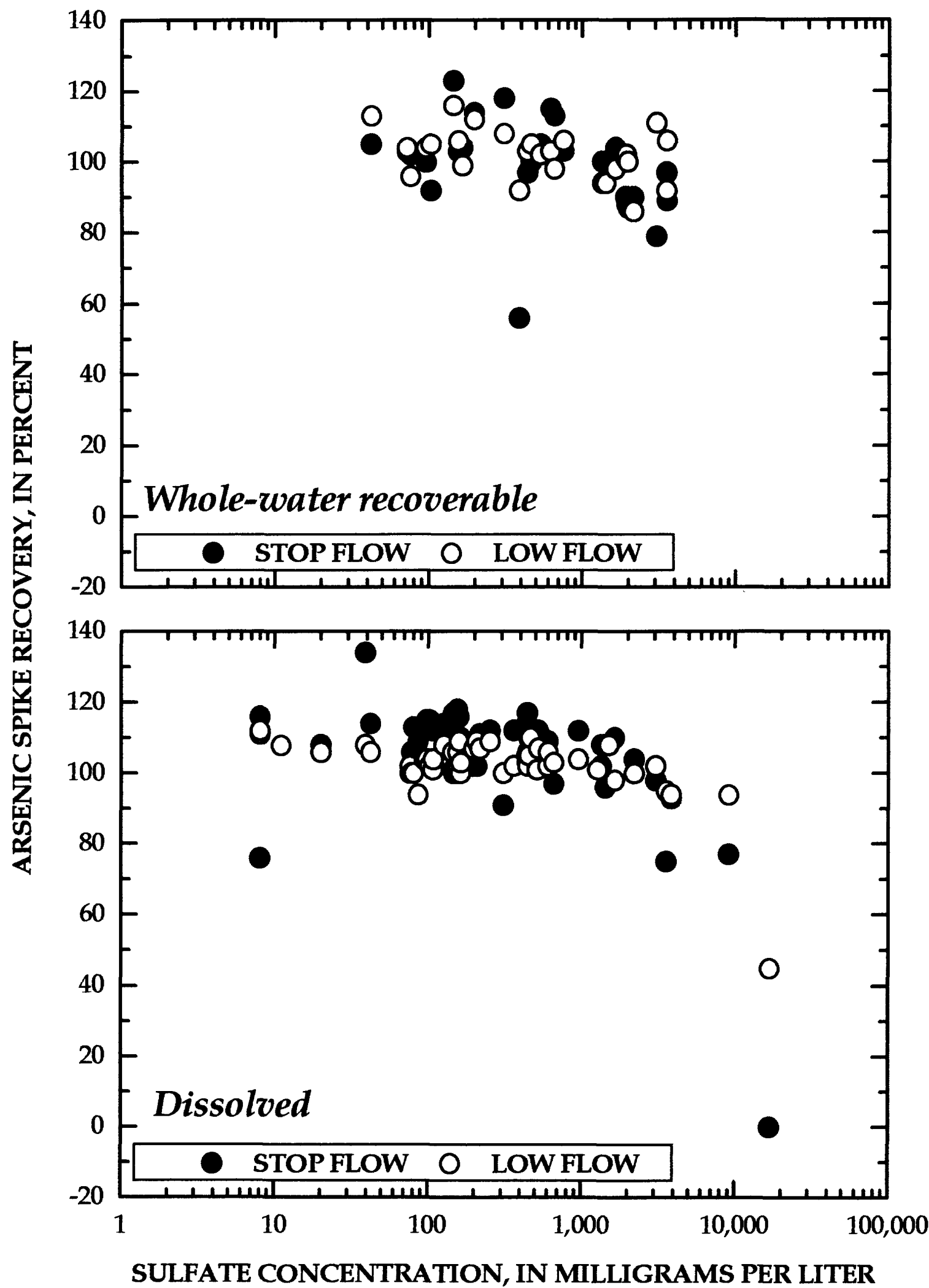

Figure 5.-- Spike recovery measurements for dissolved and whole-water recoverable arsenic by graphite furnace-atomic absorption spectrometry using stop flow and low flow during atomization in association with sulfate concentration. 


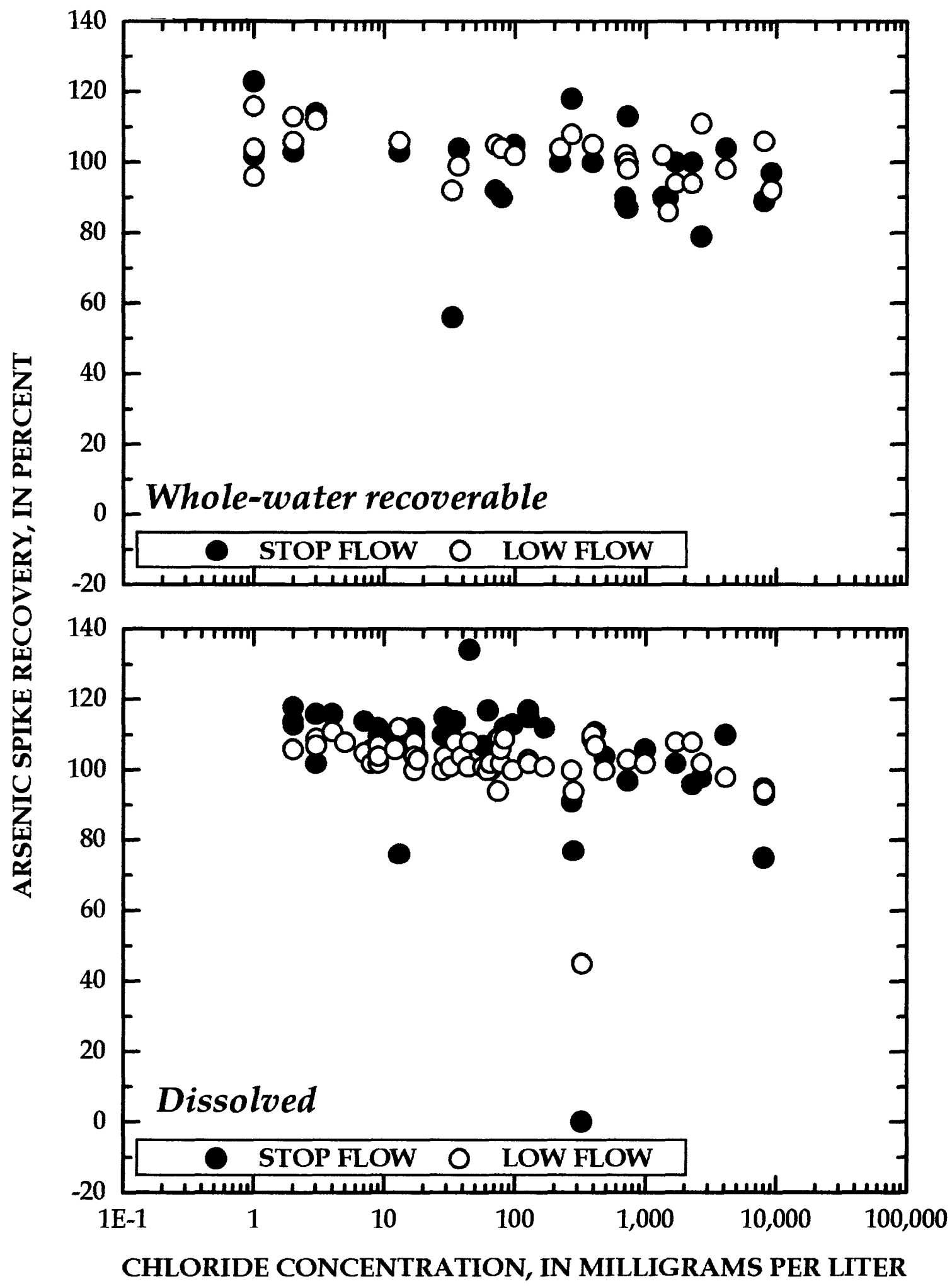

Figure 6.-- Spike recovery measurements for dissolved and whole-water recoverable arsenic by graphite furnace-atomic absorption spectrometry using stop flow and low flow during atomization in association with chloride concentration. 
generally is a good indicator of possible interferences; high specific conductance often translates to high concentrations of chloride or sulfate. However, to preclude the possibility of additional nonspectral interferences seen in more complex matrices using stop-flow conditions, low-flow conditions are indicated for routine sample analysis at the NWQL.

With acceptance criteria of 70 to 130 percent, dissolved and WWR spike recoveries for selenium (figs. 7-9) showed a distinct negative bias with increasing specific conductance and corresponding sulfate and chloride concentrations. Significant negative bias in dissolved selenium recoveries was measured for the majority of samples analyzed using stop-flow conditions when the specific conductance was greater than $1,300 \mu \mathrm{S} / \mathrm{cm}$; chloride ranged from about 150 to $8,000 \mathrm{mg} / \mathrm{L}$ and sulfate ranged from about 250 to $17,000 \mathrm{mg} / \mathrm{L}$. This trend was less significant when low-flow conditions were used.

In contrast, spike recoveries in the WWR matrix also exhibited downward trends, however, the trend is scattered and unpredictable in relation to specific conductance. When using low-flow conditions, 126 of 136 (93 percent) dissolved and WWR samples had acceptable recoveries. However, when stop-flow conditions were used, 112 of 136 (82 percent) had acceptable recoveries. Since selenium determinations using stop-flow conditions have a greater degree of interference, low-flow conditions will be used for the routine analyses. Stop-flow conditions may be requested and used for more pristine samples. As with arsenic, specific conductance might be a good indicator of potential interferences. 


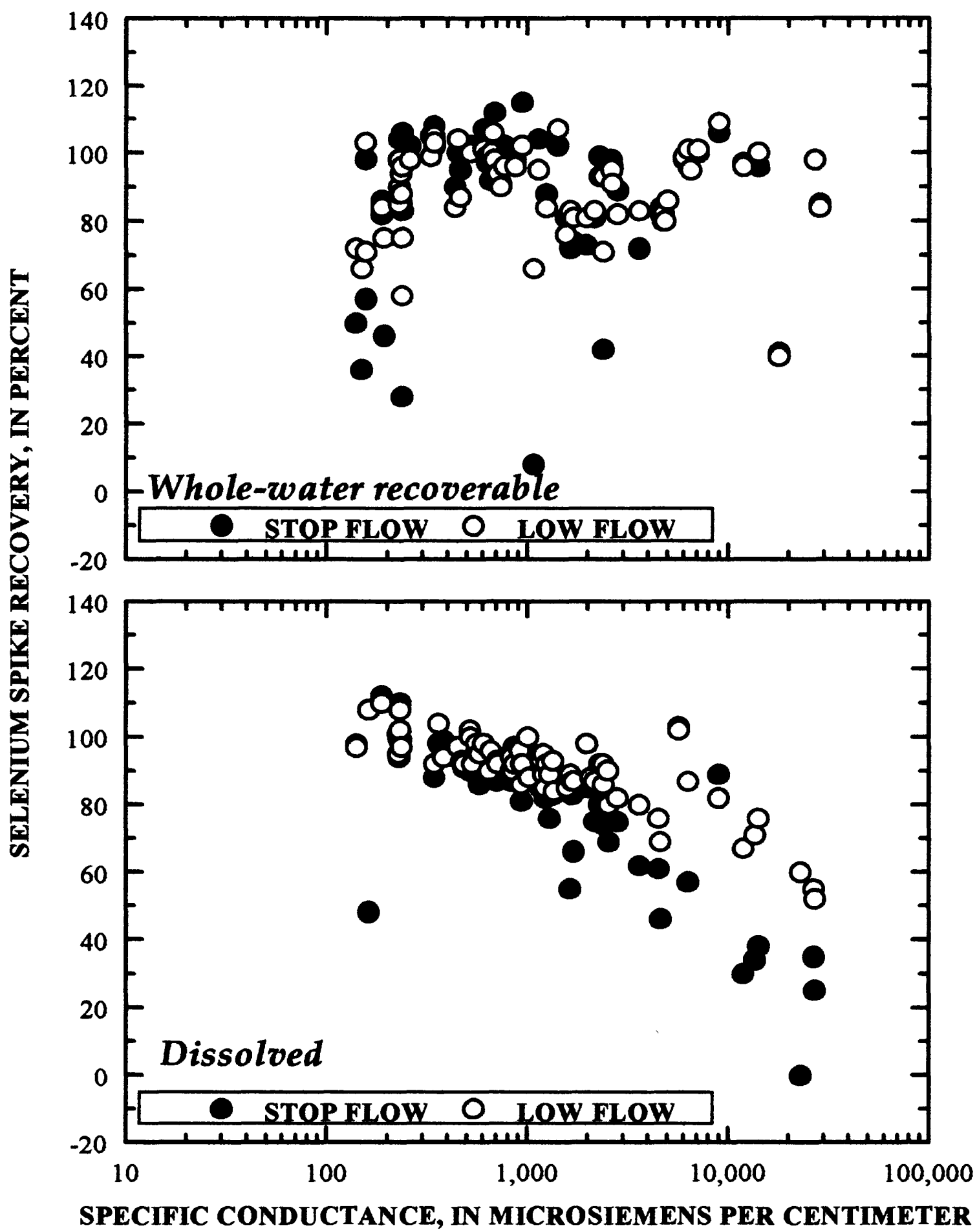

Figure 7.-- Spike recovery measurements for dissolved and whole-water recoverable selenium by graphite furnace-atomic absorption spectrometry using stop flow and low flow during atomization in association with specific conductance. 


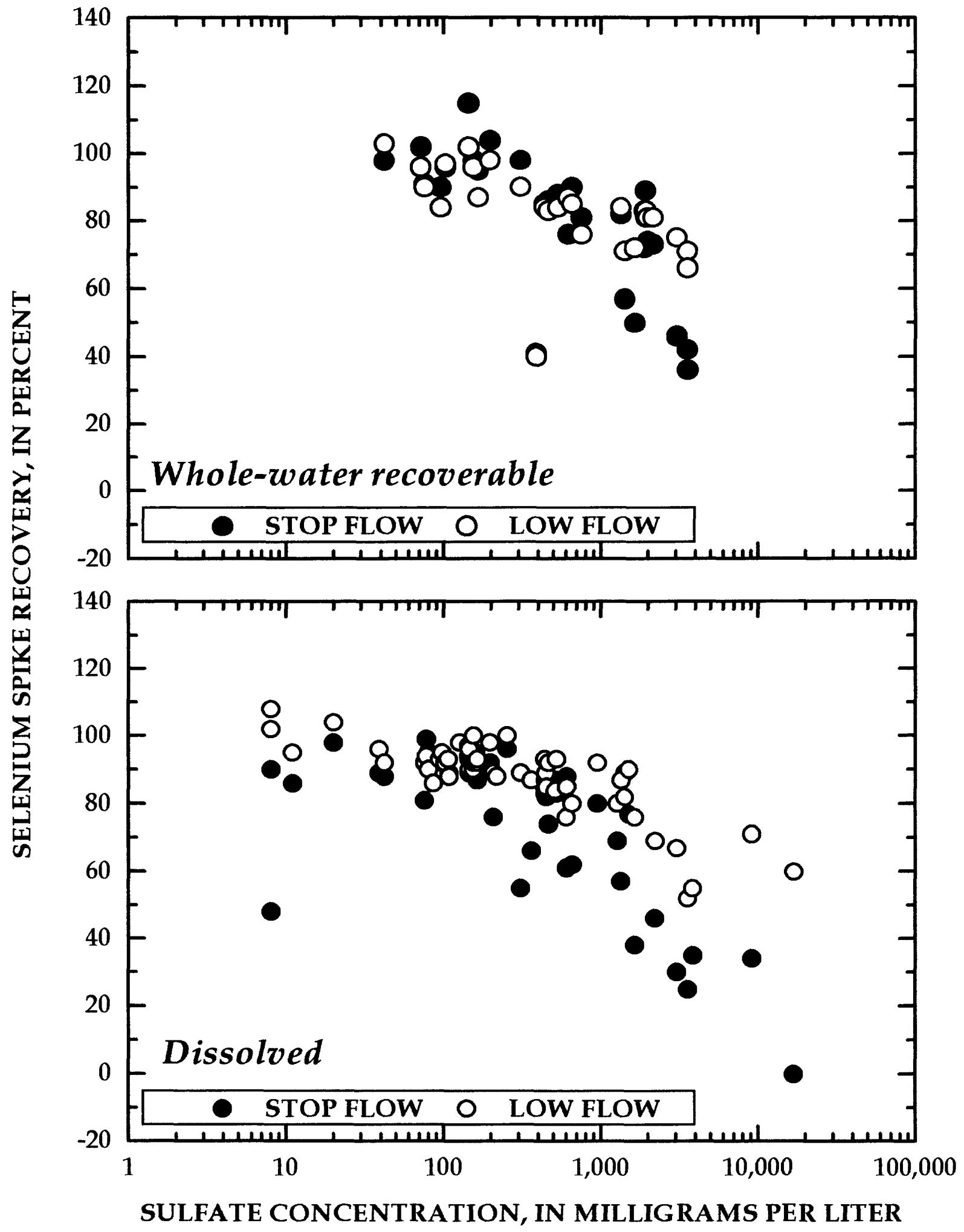

Figure 8.--Spike recovery measurements for dissolved and whole-water recoverable selenium by graphite furnace-atomic absorption spectrometry using stop flow and low flow during atomization in association with sulfate concentration. 


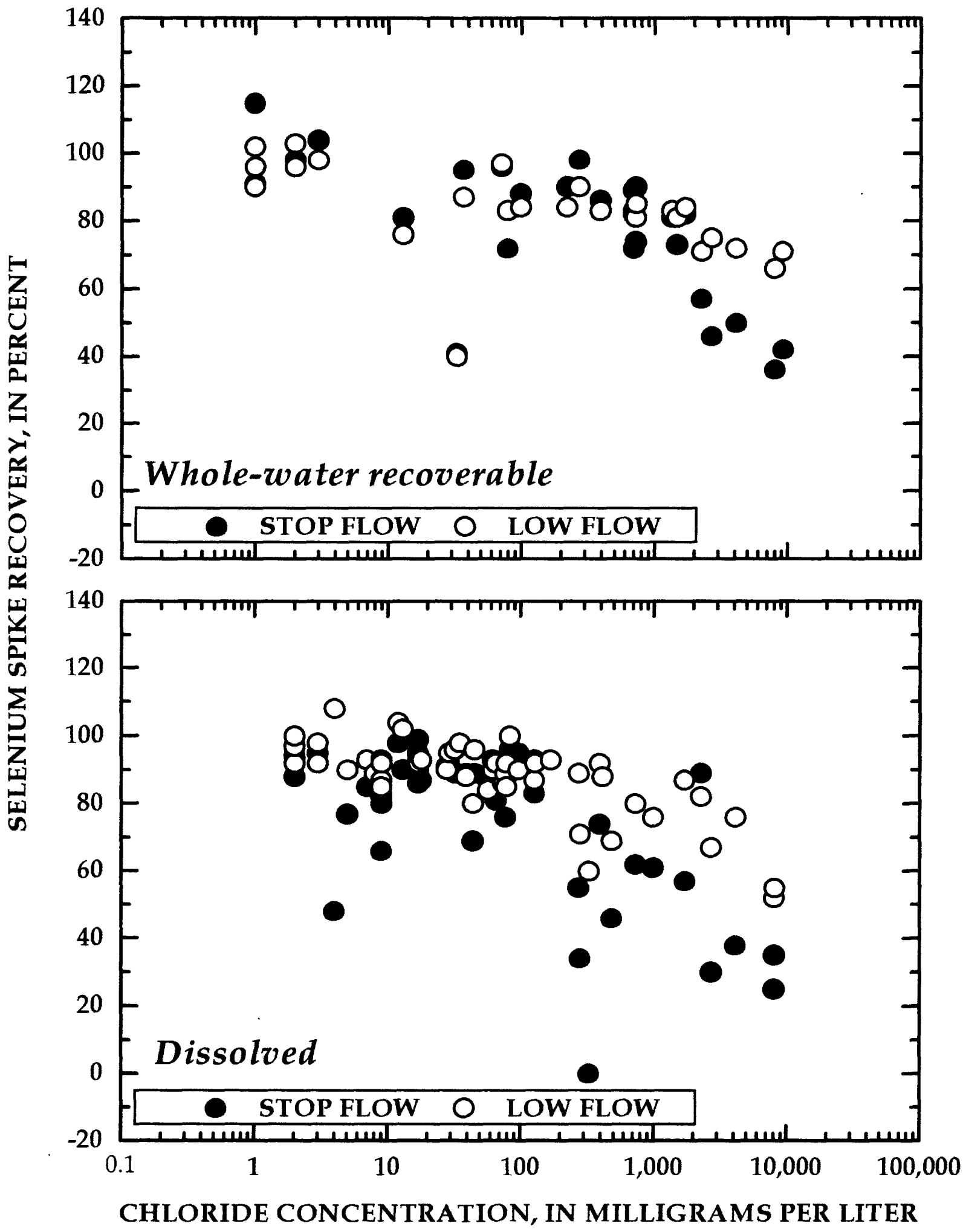

Figure 9.--Spike recovery measurements for dissolved and whole-water recoverable selenium by graphite furnace-atomic absorption spectrometry using stop flow and low flow during atomization in association with chloride concentration. 


\section{Analysis of water samples}

The same set of samples used to determine spike recoveries also was analyzed by the current HG-AAS methods and the new GF-AAS method (for a description of the sample set, see the preceding section entitled "Spike recoveries in water samples." Arsenic and selenium results were evaluated using linear regression analysis and the One Sample Sign Test; the One Sample Sign Test is used to determine whether there is a significant difference between the median values for GF-AAS and HG-AAS at the 95-percent confidence level. Both low-flow and stop-flow results from GF-AAS were used in the comparison.

Slopes, y-intercepts, and correlation coefficients from the linear regression analyses, and the p-values from the One Sample Sign Test are listed in table 9; the data points used in the linear regression analysis are shown in figures 10 through 13 . The regression analysis results show that there is no significant difference between the arsenic and selenium results from either the low-flow or stop-flow GF-AAS and HG-AAS methods. All the slopes are nearly 1.0 with the exception of dissolved selenium using stop-flow conditions; the y-intercepts are less than the MDLs except for WWR selenium using stop-flow conditions. The One Sample Sign Test results indicate that the difference between the methods is not significant for WWR arsenic by using stop flow, dissolved selenium by using low flow, and WWR selenium by using stop flow; all other results show significant difference at the 95-percent confidence level. Most median differences for those results showing significant difference were less than or equal to the MDLs; therefore, for the wide range of sample concentrations in the data set, the difference is negligible. Only WWR selenium results using low-flow $(-0.96 \mu \mathrm{g} / \mathrm{L})$ and stop-flow conditions $(1.4 \mu \mathrm{g} / \mathrm{L})$ have median differences near the MDL. 
Table 9. - Summary of statistical analysis results for graphite furnace-atomic absorption spectrometry and hydride generation-atomic absorption spectrometry

[GF-AAS, graphite furnace-atomic absorption spectrometry; HG-AAS, hydride generation-atomic absorption spectrometry; $n$, number of samples; $\mu \mathrm{g} / \mathrm{L}$, microgram per liter; $\mathrm{R}^{2}$, correlation coefficient; WWR, whole-water recoverable; $<$, less than]

\begin{tabular}{|c|c|c|c|c|c|}
\hline \multirow[b]{2}{*}{ Matrix and technique } & \multicolumn{4}{|c|}{$\begin{array}{c}\text { Linear regression of HG-AAS in } \\
\text { relation to GF-AAS }\end{array}$} & \multirow{2}{*}{$\begin{array}{c}\begin{array}{c}\text { One Sample } \\
\text { Sign Test }\end{array} \\
\text { p-value }{ }^{1}\end{array}$} \\
\hline & $\mathrm{n}$ & Slope & $\begin{array}{c}\text { y-intercept } \\
(\mu \mathrm{g} / \mathrm{L})\end{array}$ & $\mathrm{R}^{2}$ & \\
\hline $\begin{array}{l}\text { Arsenic, di } \\
\text { Low flow }\end{array}$ & 68 & 0.97 & 0.60 & 0.9689 & 0.0035 \\
\hline Stop flow & 68 & 1.1 & 0.85 & 0.8940 & $<0.0001$ \\
\hline
\end{tabular}

Arsenic, WWR

Low flow

$51 \quad 1.0$

1.0

0.62

0.9577

0.0500

Stop flow

$50 \quad 1.0$

0.15

0.9473

1.000

Selenium, dissolved

Low flow

68
67.96

0.67

0.9435

0.0684

Stop flow

$\begin{array}{ll}67 & 0.93\end{array}$

$-1.6$

0.8028

$<0.0001$

Selenium, WWR

Low flow

70

0.99

1.0

0.9125

0.0017

Stop flow

70

1.0

1.6

0.8059

0.1306

${ }^{1}$ The null hypothesis infers the difference between GF-AAS and HG-AAS results is zero. 


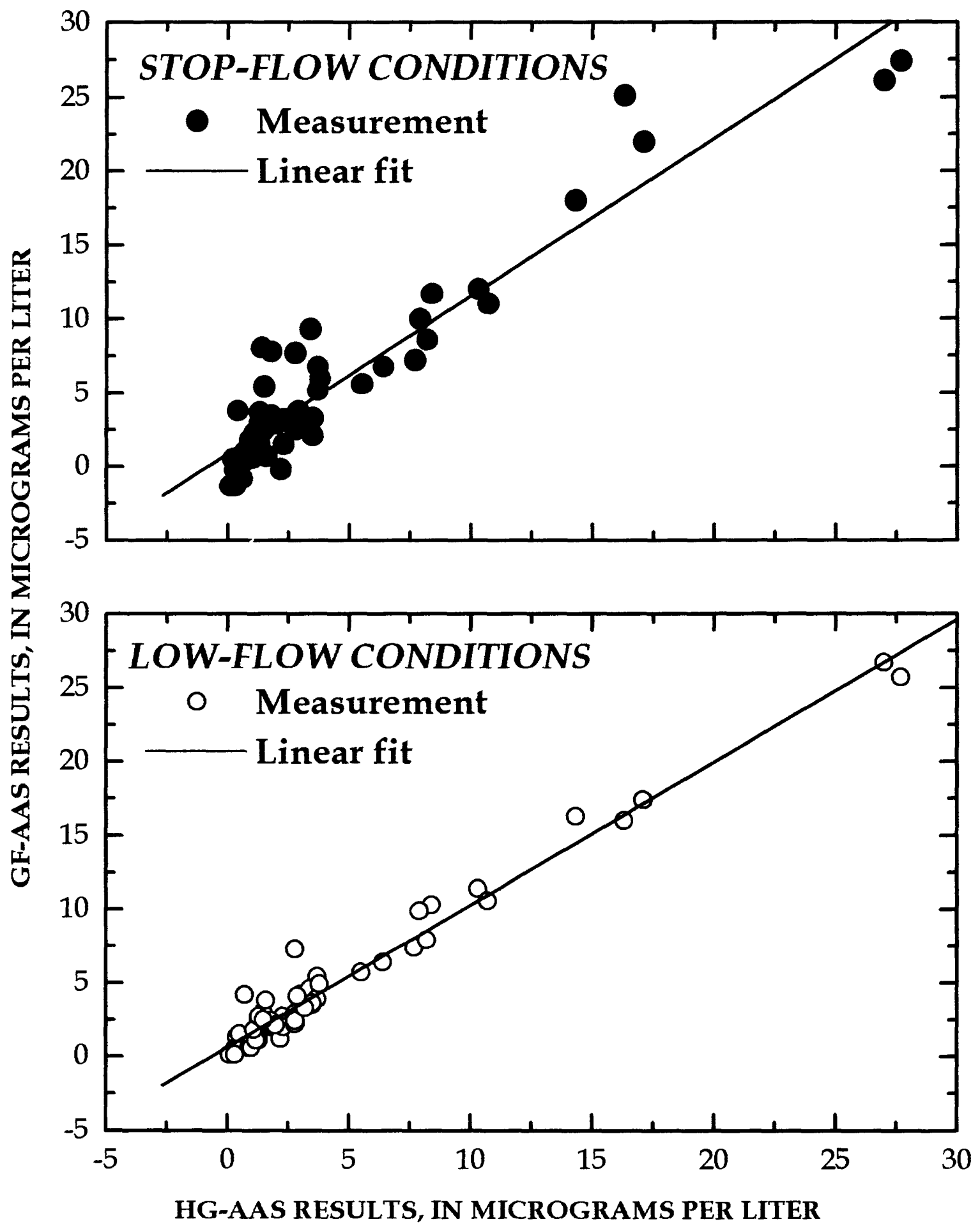

Figure 10.--Results for the determination of dissolved arsenic in filtered water samples analyzed by graphite furnace-atomic absorption spectrometry (GF-AAS) using stop-flow and low-flow conditions relative to hydride generation-atomic absorption spectrometry (HGAAS). 


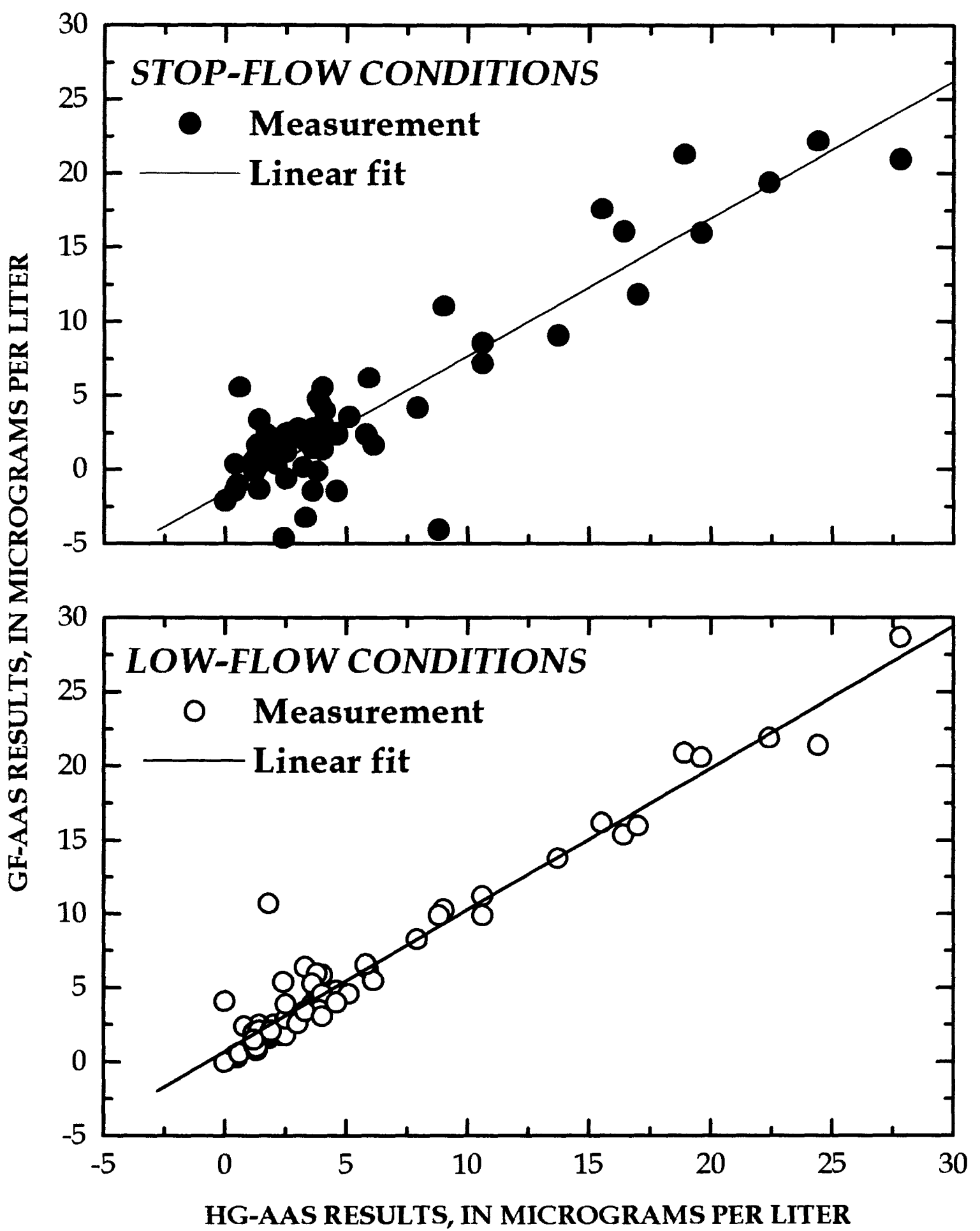

Figure 11.--Results for the determination of dissolved selenium in filtered water samples analyzed by graphite furnace-atomic absorption spectrometry (GF-AAS) using stop-flow and low-flow conditions relative to hydride generation-atomic absorption spectrometry (HGAAS). 


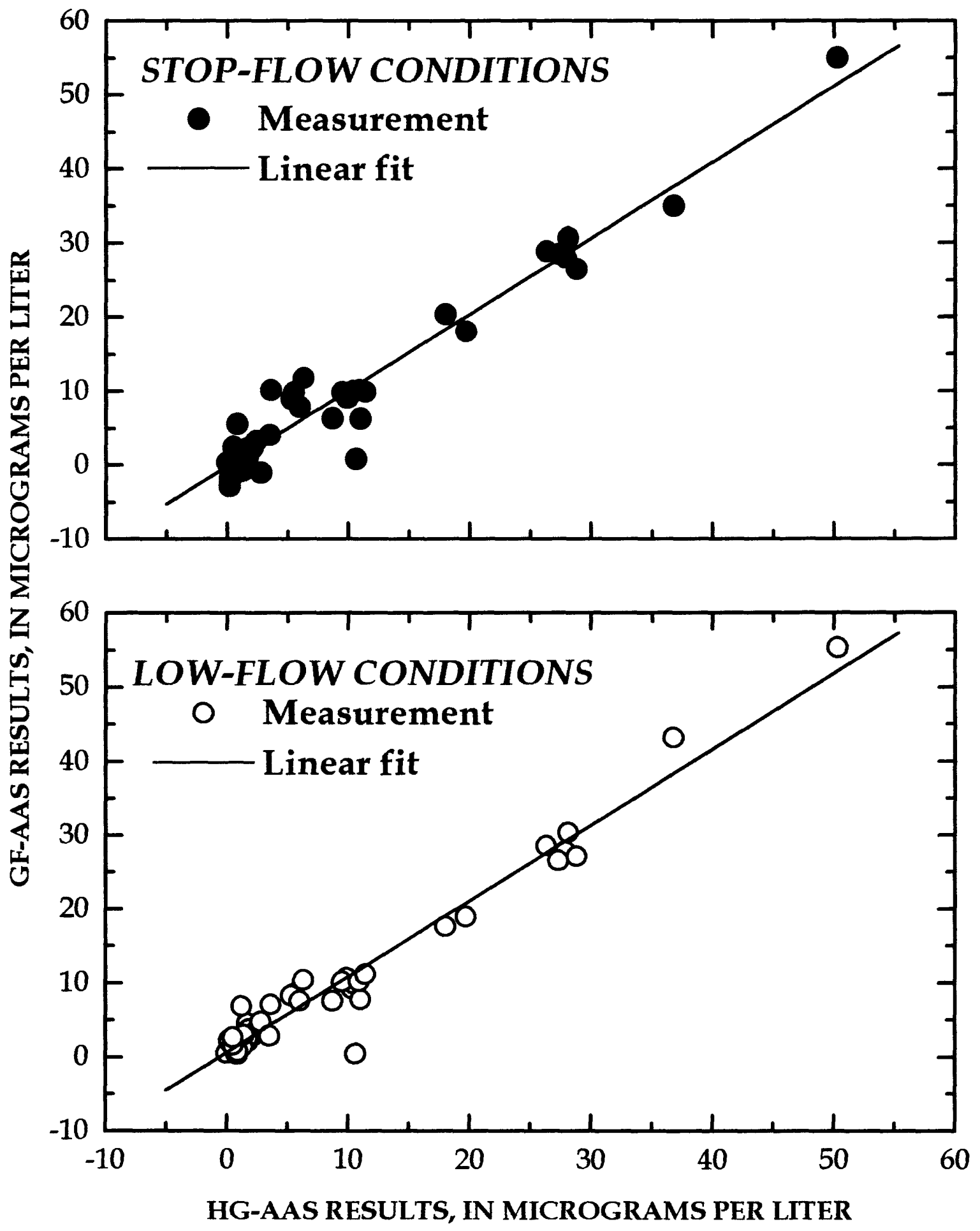

Figure 12.--Results for the determination of whole-water recoverable arsenic in nonfiltered water samples analyzed by graphite furnace-atomic absorption spectrometry (GF-AAS) using stop-flow and low-flow conditions relative to hydride generation-atomic absorption spectrometry (HG-AAS). GF-AAS uses the in-bottle digestion and HG-AAS uses an on-line digestion procedure. 


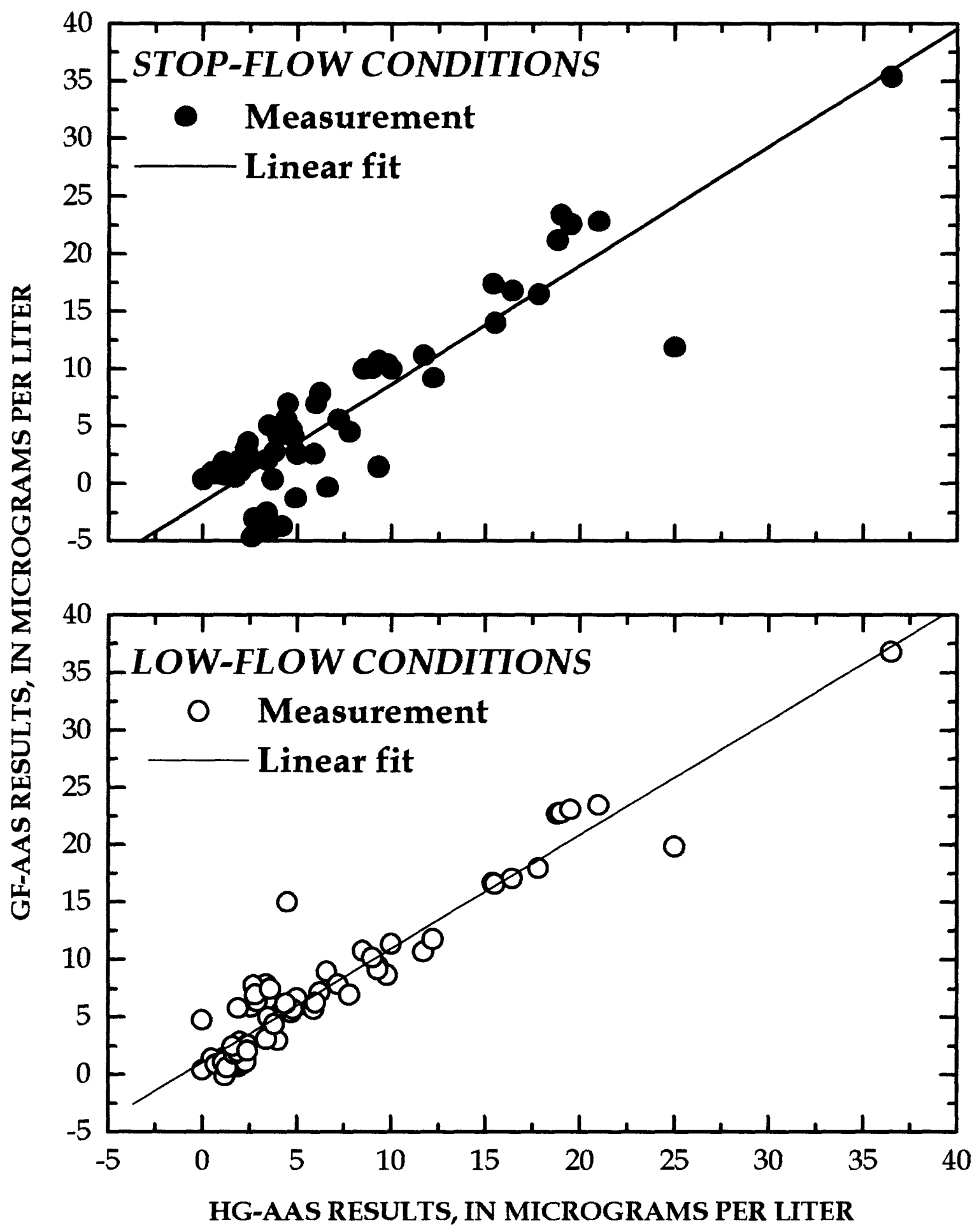

Figure 13.--Results for the determination of whole-water recoverable selenium in nonfiltered water samples analyzed by graphite furnace-atomic absorption spectrometry (GF-AAS) using stop-flow and low-flow conditions relative to hydride generation-atomic absorption spectrometry (HG-AAS). GF-AAS uses the in-bottle digestion and HG-AAS uses an on-line digestion procedure. 


\section{QUALITY ASSURANCE}

Minimum quality-control requirements per set must include analysis of a laboratory reagent blank and quality-control samples, such as SRWS, and may include check standards, sample duplicates, and sample spikes. A WWR or bed-sediment sample set must include a synthetic whole-water sample that is based on a standard reference material and reagent blank carried through the digestion process to verify the accuracy of the procedure. Field spikes and duplicates are suggested as additional checks. Detailed descriptions of quality-control requirements and corrective measures are included in the method Standard Operating Procedure IM0316.0 (S.R. Jones, U.S. Geological Survey, written commun., 1998). Refer to Pritt and Raese (1995) for a discussion regarding inorganic quality-control requirements.

\section{CONCLUSIONS}

The graphite furnace-atomic absorption spectrometry technique has been shown to be capable of determining arsenic and selenium in water and sediment accurately. Performance of the method for the determination of arsenic and selenium was supported by the accuracy obtained for standard reference materials, spike recovery samples, and water samples. The method provides the following advantages:

- Method detection limits are similar to the hydride generation-atomic absorption spectrometry methods (about $1 \mu \mathrm{g} / \mathrm{L}$ ).

- Arsenic and selenium are determined simultaneously on a single sample aliquot.

- Bias and variability are comparable to the former methods.

- Potential of chemical interferences is minimal for routine sample matrices.

- In-bottle digestion procedure is more accurate than the former on-line digestion procedure for the determination of recoverable arsenic in unfiltered water and bed sediment. Either the $\mathrm{HCl}$ or the $\mathrm{HNO}_{3}$ in-bottle digestion procedure can be used, however, the $\mathrm{HNO}_{3}$ inbottle procedure reduces the potential for interferences.

- In-bottle digestion procedure used in the subject method is used by other methods at the National Water Quality Laboratory, thereby reducing the number of required digestion procedures.

- Sample throughput is increased.

- Smaller sample volumes are required.

- Number of chemical reagents required is substantially reduced.

- Amount of chemical waste produced is substantially reduced.

This new method most likely will not impact long-term water-quality studies that use dissolved arsenic and selenium results for trend analysis. Possible bias, however, might be identified in whole-water recoverable and total recoverable bed-sediment analyses for arsenic and selenium results, depending on the sample matrix. 


\section{REFERENCES CITED}

American Society for Testing and Materials, 1995, Annual book of ASTM standards, Section II, Water: Philadelphia, v. 11.01, p. 122-124.

Beaty, R.D., 1988, Concepts, instrumentation and techniques in atomic absorption spectrometry: Perkin Elmer Corp., chaps. 5 and 6, variable pagination.

Beaty, R.D., and Kerber, J.D., 1993, Concepts, instrumentation and techniques in atomic absorption spectrometry: Perkin Elmer Corp., chaps. 5 and 6.

Creed, J., Martin, T., Lobring, L., and O' Dell, J., 1992, Minimizing chloride interferences produced by combination acid digestion using palladium and hydrogen as a matrix modifier in graphite furnace-atomic absorption spectrometry: Environmental Science Technology, v. 26, p. 102-106.

Fishman, M.J., and Friedman, L.C., 1989, Methods for determination of inorganic substances in water and fluvial sediments: U.S. Geological Survey Techniques of Water-Resources Investigations, book 5, chap. A1, $545 \mathrm{p}$.

Frech, W., and L'Vov, B.V., 1993, Matrix vapours and physical interference effects in graphite furnace-atomic absorption spectrometry -II. Side-heated tubes: Spectrochimica Acta, v. 48B, no. 11, p. 1371-1379.

Flajnik-Rivera, C. and Delles, F., 1996, Evaluation of deuterium and Zeeman background correction with the presence of spectral interferences-Determinations of arsenic and selenium in an iron matrix by GFAA: American Environmental Laboratory, p. 24-27.

Ghe, A.M., Carati, Daniela, and Stefanelli, Claudio, 1983, Determination of trace amounts of arsenic and selenium by flame and flameless atomic absorption spectrometry: Annali di Chimica, p. 711.

Hoffman, G.L., Fishman, M.N., and Garbarino, J.R., 1996, Methods of analysis by the U.S. Geological Survey National Water Quality Laboratory - In-bottle acid digestion of whole-water samples: U.S. Geological Survey Open-File Report 96-225, 28 p.

Lindberg, I., Lundberg, E., Arkhammar, P., and Berggren, P., 1988, Direct determination of selenium in solid biological materials by graphite furnace-atomic absorption spectrometry: Journal of Analytical Spectrometry, v. 3, p. 497.

Pritt, J.W., and Raese, J.W., 1995, Quality assurance/quality control manual-National Water Quality Laboratory: U.S. Geological Survey Open-File Report 95-443, 35 p. 
U.S. Environmental Protection Agency, 1994a, Guidelines establishing test procedures for the analysis of pollutants (Part 136, Appendix B. Definition and Procedure for the Determination of the Method Detection Limit-Revision 1.11): U.S. Code of Federal Regulations, Title 40, Revised as of July 1, 1994, p. 635-637.

1994b, Determination of trace elements by stabilized temperature graphite furnace atomic absorption: Cincinnati, Ohio, Revision 2.2, p. 21.

9 Printed on recycled paper 